\title{
Pharmacokinetics-pharmacodynamics issues relevant for the clinical use of beta- lactam antibiotics in critically ill patients
}

Rui Pedro Veiga ${ }^{1,2,3^{*}}$ (DD and José-Artur Paiva ${ }^{1,2,3}$

\begin{abstract}
Antimicrobials are among the most important and commonly prescribed drugs in the management of critically ill patients and beta-lactams are the most common antibiotic class used. Critically ill patient's pathophysiological factors lead to altered pharmacokinetics and pharmacodynamics of beta-lactams.

A comprehensive bibliographic search in PubMed database of all English language articles published from January 2000 to December 2017 was performed, allowing the selection of articles addressing the pharmacokinetics or pharmacodynamics of beta-lactam antibiotics in critically ill patients.

In critically ill patients, several factors may increase volume of distribution and enhance renal clearance, inducing high intra- and inter-patient variability in beta-lactam concentration and promoting the risk of antibiotic underdosing. The duration of infusion of beta-lactams has been shown to influence the fT > minimal inhibitory concentration and an improved beta-lactam pharmacodynamics profile may be obtained by longer exposure with more frequent dosing, extended infusions, or continuous infusions.

The use of extracorporeal support techniques in the critically ill may further contribute to this problem and we recommend not reducing standard antibiotic dosage since no drug accumulation was found in the available literature and to maintain continuous or prolonged infusion, especially for the treatment of infections caused by multidrug-resistant bacteria.

Prediction of outcome based on concentrations in plasma results in overestimation of antimicrobial activity at the site of infection, namely in cerebrospinal fluid and the lung. Therefore, although no studies have assessed clinical outcome, we recommend using higher than standard dosing, preferably with continuous or prolonged infusions, especially when treating less susceptible bacterial strains at these sites, as the pharmacodynamics profile may improve with no apparent increase in toxicity.

A therapeutic drug monitoring-guided approach could be particularly useful in critically ill patients in whom achieving target concentrations is more difficult, such as obese patients, immunocompromised patients, those infected by highly resistant bacterial strains, patients with augmented renal clearance, and those undergoing extracorporeal support techniques.
\end{abstract}

Keywords: Critical care or intensive care or critically ill, Sepsis or septic shock, Antibiotics, Pharmacokinetics, Pharmacodynamics

\footnotetext{
* Correspondence: ruipedroveiga@gmail.com

${ }^{1}$ Centro Hospitalar São João, EPE - Intensive Care Department, Porto,

Portugal

${ }^{2}$ Faculty of Medicine - University of Porto, Porto, Portugal

Full list of author information is available at the end of the article
}

(c) The Author(s). 2018 Open Access This article is distributed under the terms of the Creative Commons Attribution 4.0 International License (http://creativecommons.org/licenses/by/4.0/), which permits unrestricted use, distribution, and reproduction in any medium, provided you give appropriate credit to the original author(s) and the source, provide a link to the Creative Commons license, and indicate if changes were made. The Creative Commons Public Domain Dedication waiver (http://creativecommons.org/publicdomain/zero/1.0/) applies to the data made available in this article, unless otherwise stated. 


\section{Background}

Antimicrobials are among the most important and commonly prescribed drugs in the management of critically ill patients and beta-lactams are the most common antibiotic class used because of their broad spectrum of activity and high tolerability $[1,2]$.

Early and appropriate antibiotic administration improves clinical outcome of septic patients [3-7]. In the presence of septic shock, besides conflicting results [8, 9], each hour delay is associated with a measurable increase in mortality and other negative endpoints (e.g., length of stay in ICU, acute kidney injury, acute lung injury, and global organ injury assessed by the Sepsis-Related Organ Assessment score) [10, 11].

Choosing the appropriate antimicrobial for the bacterial activity spectrum is crucial but the correct dosage regimen (both dose and frequency) is, at least, of the same importance for successful clinical cure and microbiological eradication [11].

Unlike organotropic drugs, where it is easy to titrate dose to achieve a clinical response, antibiotics may take 24-72 h to present signs of resolution of infection, making it difficult to determine the most appropriate dosage $[1,2]$.

We conducted a comprehensive bibliographic search in the PubMed database of all English language articles published from January 2000 to December 2017, using the following keywords: critical care or intensive care or critically ill and sepsis or septic shock and antibiotics and pharmacokinetics or pharmacodynamics. Articles not addressing beta-lactam pharmacokinetics (PK) or pharmacodynamics (PD) in critically ill patients were excluded. A small number of articles derived from references in the articles selected were also reviewed. In the end, 214 studies were included in our review (Fig. 1).

\section{Beta-lactam PD characteristics}

Knowledge of the antimicrobial PD characteristics (inhibition of growth, rate and extent of bactericidal action, and post-antibiotic effect (PAE)) provides a more rational basis for determination of optimal dosing regimens in terms of the dose and the dosing interval.

The antimicrobial activity of drugs is usually assessed by determination of the minimum inhibitory concentration (MIC) and the minimum bactericidal concentration $(\mathrm{MBC})$ of the drug under specific conditions in vitro. These in vitro conditions are very different from those expected at the site of infection, where the milieu is frequently acidic and anaerobic, and tissue protein may bind a variable amount of the drug. Additionally, these parameters do not provide information on the time course of the antimicrobial effect-the fluctuating levels that are present in a patient treated with the drug-and are measured against a standard bacterial inoculum (about 10 colony-forming units (CFU) per millilitre [5])

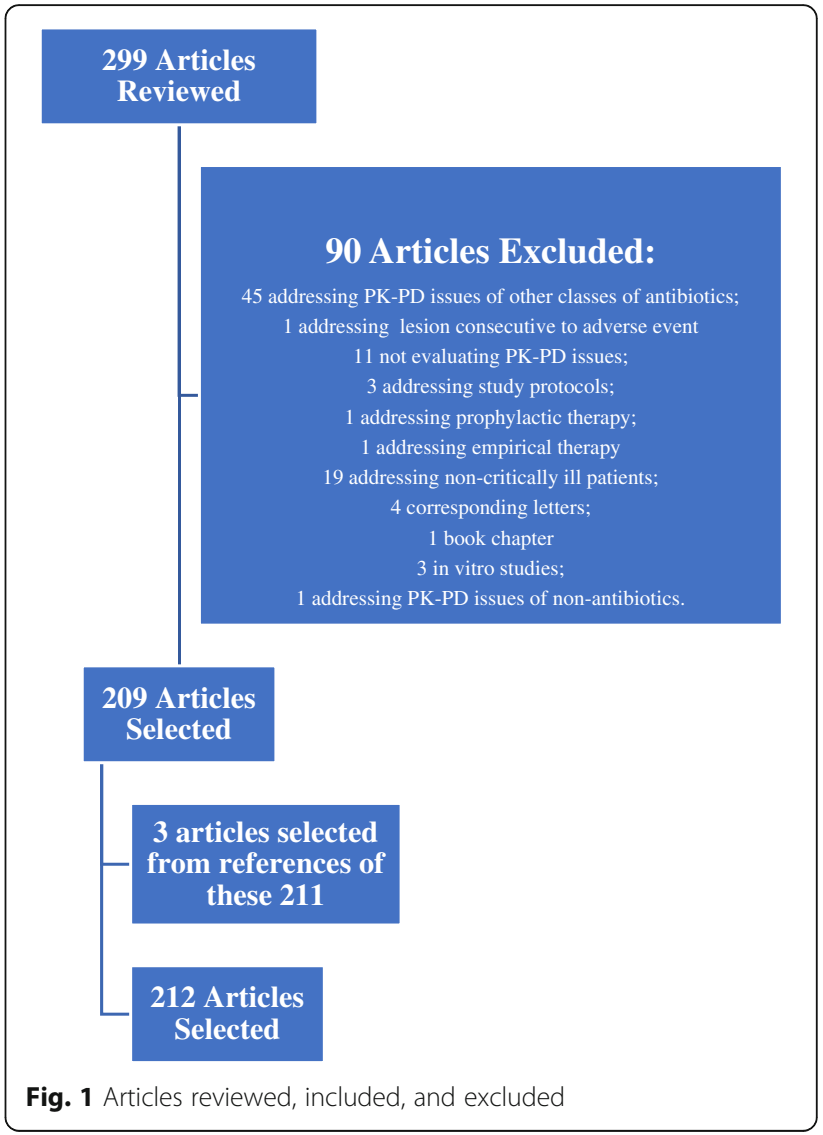

that does not necessarily correspond to bacterial densities at site of infection (10 CFU per gram of tissue or pus [8-10]). For bactericidal drugs, the MBC is generally not more than fourfold higher than the MIC. The size of the residual bacterial population at the end of each dosing interval, and ultimately the efficacy of the antimicrobial regimen, depends on the interplay of a variety of bacterial, drug, and host factors that include the size of the initial bacterial population, the potency (MIC and $\mathrm{MBC}$ ) and PK characteristics of the antimicrobial agent, the rate and extent of any bactericidal effect, the presence of a post-antibiotic effect (PAE), the rate of re-growth of persistent organisms, and the state of host defences [13].

Three PD indices describe optimal killing associated with antibiotics: $\mathrm{fT}>\mathrm{MIC}$, which is the amount of time that the unbound drug concentration remains above the MIC of the infecting organism; $C_{\text {max }} / \mathrm{MIC}$, which is the ratio between the maximum concentration of the drug and the MIC of the infecting organism; and $\mathrm{AUC}_{0-24} /$ $\mathrm{MIC}$, which is the ratio between total area under the concentration-time curve (AUC) over $24 \mathrm{~h}$ and the MIC of the infecting organism.

Beta-lactams are time-dependent antimicrobials whose efficacy is mainly related to $\mathrm{fT}>\mathrm{MIC}[1,2,12-14]$. 
Increasing drug concentrations much above the $\mathrm{MBC}$ does not enhance bacterial killing and the bactericidal action of these drugs is relatively slow. When drug levels at the site of infection fall below the MIC, the relatively large residual population can resume growth quickly because most beta-lactams either have no or only a short PAE [12]. McKinnon et al. compared the PD of cefepime and ceftazidime and observed that patients with $\mathrm{fT}>\mathrm{MIC}$ of $100 \%$ had significantly greater rates of clinical cure and bacteriological eradication than patients with $\mathrm{fT}>\mathrm{MIC}$ of $<100 \%$ [15].

It is suggested that $50 \% \mathrm{fT}>\mathrm{MIC}$ of the dosage interval is needed to ensure standard efficacy with these antimicrobials, whereas $100 \% \mathrm{fT}>\mathrm{MIC}$ of the dosage interval should be ensured for optimal exposure in immunocompromised patients. A further improvement in efficacy is observed when antibiotic concentrations are four to five times greater than MIC $[2,12,13]$. The percentage of time above MIC that correlates with efficacy varies among different beta-lactam groups, being greater for cephalosporins and aztreonam than for penicillins, and greater for penicillins than for carbapenems. Also, variations occur among different bacterial species, being less for staphylococci, for which beta-lactams have a PAE, than for streptococci and Gram-negative bacilli, for which beta-lactams do not have a PAE $[2,13]$.

\section{Beta-lactam PK issues in the critically ill}

Discovered antibiotics are evaluated in vitro and tested in animals, initially for toxicity and subsequently for efficacy. The antibiotic dose and frequency are based on these in vitro or animal in vivo PK/PD studies. These dosing regimens are then tested on healthy human volunteers for tolerability, with clinical efficacy studies undertaken in non-critically ill patients. After the launch of the drug onto the general market, the same dosing regimen is used in critically ill patients; however, this is likely to lead to suboptimal outcomes in the ICU [5], especially with more resistant bacterial strains [16] and in the immunocompromised population [17].

Beta-lactams are hydrophilic drugs and so their volume of distribution (Vd) is low and similar to that of extracellular water. Variations in the extracellular fluid content and/or in renal or liver function may be considered the most relevant and frequent pathophysiological mechanisms possibly affecting drug disposition in critically ill patients. Other factors may contribute to altered antibiotic concentrations: an interesting case-report by Taccone et al. [18] related the case of an obese septic patient with Pseudomonas aeruginosa pneumonia treated with meropenem. The PD target $(t>4 \times \mathrm{MIC}>40 \%$ of the dosing interval) was only achievable by dosing $3 \mathrm{~g}$ q6h at $3 \mathrm{~h}$ extended infusion and was associated with clinical improvement.
Compared with healthy volunteers and non-critically ill patients, in critically ill patients capillary leakage and edema, fluid therapy, pleural effusion, ascites, indwelling post-surgical drainage, and hypoalbuminemia may increase $\mathrm{Vd}$ and cause antibiotic dilution in plasma and extracellular fluids. Some pathophysiological factors may also enhance (trauma, burns, the hyperdynamic condition of the early phase of sepsis, the use of hemodynamically active drugs) or reduce (renal failure, muscular wastage, bedridden patients) renal clearance and consequently may alter plasma and extracellular antibiotic concentrations (with implications on time over MIC), induce high intraand inter-patient variability, and promote the risk of antibiotic underdosing $[1,2,12,14,19-35]$. Extracorporeal support techniques also contribute to antibiotic concentration variability [36].

PK studies on ICU septic patients reported, overall, increased Vd with significant daily concentration fluctuations between and within patients [5, 36-41]. Clearance of drugs is also affected and usually related to creatinine clearance [1, 42-44]. A single-center study of 17 ICU patients with ventilator-associated pneumonia (VAP) described the PK profile of ertapenem and concluded that, because of its highly protein-bound profile, hypoalbuminemia resulted in a higher protein-unbound fraction with consequences for drug distribution and elimination [38]. Ulldemolins et al. [39] found the same while studying the PK profile of flucloxacillin. Ramon-Lopez et al. [45] described high PK variations (between and within patients) for meropenem in 12 burn ICU patients that were mostly related to age, body weight, and serum albumin. Carlier et al. [37] investigated the adequacy of piperacilin/tazobactam dosing and its trough variability during an entire 7-day antibiotic course in $11 \mathrm{ICU}$ patients with pneumonia and normal renal function. Six of them failed to achieve the PK/PD target of $100 \% \mathrm{fT}>$ $\mathrm{MIC}$ at least once during the treatment course and considerable antibiotic concentration variability was found within and between patients. The DALI study, a large multicenter prospective study evaluated 248 ICU patients treated for infection with beta-lactams and found large variations on beta-lactam blood concentrations. The achievement of the PK/PD targets was highly inconsistent, with one fifth of the patients not achieving their most conservative PK/PD target of 50\% $\mathrm{fT}>\mathrm{MIC}$ and better outcomes were described with higher drug exposure, at least for less severely ill patients [5].

Septic patients with acute renal failure may have suboptimal antibiotic concentrations in the first days of therapy when the recommended dosing adjustment for renal failure is used [46]. Taconne et al. [40] studied the PK profiles of four beta-lactams (ceftazidime, cefepime, piperacilin/tazobactam, and meropenem) over the first $24 \mathrm{~h}$ of treatment in 80 septic ICU patients. They 
concluded that, besides high intra- and inter-patient PK variability, standard first doses of broad-spectrum $\beta$-lactams provided inadequate levels to achieve target serum concentrations for extended periods of time.

Augmented renal clearance has probably more impact than altered Vd on the PK of beta-lactams [25, 27, 47-54]. Roberts et al. [23] described the PK of cefazolin in plasma and interstitial fluid of subcutaneous tissue in post-trauma critically ill patients and demonstrated that increasing creatinine clearance $(\mathrm{ClCr})$ or decreasing serum albumin concentrations will reduce the likelihood of achieving optimal cefazolin exposure in subcutaneous interstitial tissue. In the presence of augmented renal clearance $(\mathrm{ClCr}$ $>130 \mathrm{~mL} / \mathrm{min}$ ), a much higher dose of cefazolin is required to obtain similar relative drug exposures [23]. Conil et al. [43] found that higher $\mathrm{ClCr}$ values $(>50 \mathrm{~mL} / \mathrm{min}$ ) did not provide trough concentrations of piperacilin (4 g three times a day) sufficient enough to attain the MIC for many pathogens in many of the patients studied.

Hypoalbuminemia has also been associated with altered PK. Wong et al. [55] described a linear correlation between the percentage protein binding of flucloxacillin and the plasma albumin concentration, though this was not true for ceftriaxone. Also, plasma albumin concentrations and in vitro binding data from healthy volunteers should not be used to predict unbound concentrations of ceftriaxone in ICU patients [56].

\section{Use of extracorporeal support techniques in critical care}

Acute kidney injury (AKI) occurs in 50 to $65 \%$ of critically ill patients and in approximately two-thirds of patients within the first $24 \mathrm{~h}$ after admission to the intensive care unit (ICU) [57]. Critically ill patients are usually supported with one of the forms of continuous renal replacement therapy (CRRT)-continuous venous-venous hemofiltration, hemodiafiltration, hemodialysis (CVVHF, CVVHDF, CVVHD, respectively) - or with sustained low-efficiency dialysis (SLED). Molecules are transported across the filter membrane by the mechanism of convection (driven by the pressure gradient-CVVHF), diffusion (driven by the concentration gradient-CVVHD, SLED), or both (CVVHDF).

Employing CRRT complicates antibiotic dosing to a significantly higher extent than standard hemodialysis due to the high number of variables, including Vd, flow of the dialysis fluid, replacement fluid infusion site (preor post-dilution mode), type and surface of the used membrane, and the difference between delivered and prescribed RRT dose.

Vd in AKI may be significantly different from published population estimates derived from healthy subjects. Besides the decreased plasma protein concentrations in acutely ill patients, uremic solutes, such as hippurate and indoxyl sulfate, alter drug binding to albumin in chronic renal failure and might do so in acute renal failure, although this has not been tested. The free fraction of many drugs is increased in renal failure, even though the $\mathrm{Vd}$ for total drug may increase due to movement of unbound drug into interstitial or total body water [57-59].

Overall, a tendency for antibiotic underdosing in critically ill patients on CRRT or SLED likely exists. The mode and dose of CRRT vary quite widely from center to center and from report to report, making it very difficult to create generally applicable beta-lactam dosing guidelines for critically ill patients under CRRT. Additionally, antibiotic concentrations may vary depending on the degree of extraction and residual renal function, which is variable, difficult to assess, and rarely considered despite its relevant contribution to antibiotic clearance in patients undergoing CRRT (Tables 1 and 2) [60-96].

Globally, we recommend not reducing standard antibiotic dosage since no drug accumulation was found in the available literature and to maintain continuous or prolonged infusion in critically ill patients on CRRT, SLED, or EDD, especially for the treatment of multidrug-resistant bacteria. Although usually not available in clinical routines, a therapeutic drug monitoring (TDM)-guided strategy has potential benefit to ensure appropriate antibiotic therapeutic targets.

Extracorporeal membrane oxygenation (ECMO) has become an essential tool for severe cardiorespiratory failure in critically ill patients. It is thought to introduce additional confounding factors to the already altered PK properties of beta-lactams in this subset of patients. Sequestration of antibiotics in the ECMO circuit and the associated systemic inflammation can further increase the antibiotic $\mathrm{Vd}$ and reduce clearance [74, 97-99]. However, very few in vivo studies have been performed in this subset of patients (Table 3). Globally, they show no significant statistical variation in $\mathrm{Vd}$ and clearance, but while probability of target attainment (PTA) with standard ICU dosage regimens was achieved when treating for highly susceptible Gram-negative bacteria, antibiotic concentrations were below those desired to treat more resistant strains.

\section{Longer exposure regimens: continuous infusion, extended infusion, or reduced-interval dosing}

The duration of infusion of beta-lactams has been shown to influence their $\mathrm{fT}>\mathrm{MIC}$. Improved PD profiles of beta-lactams may be obtained by longer exposure with more frequent dosing, extended infusions, or continuous infusions. Several studies reported PD benefits for target attainment of extended and continuous infusions, especially considering highly resistant bacterial strains, even using smaller daily doses $[1,2,36,41,103-143]$. 


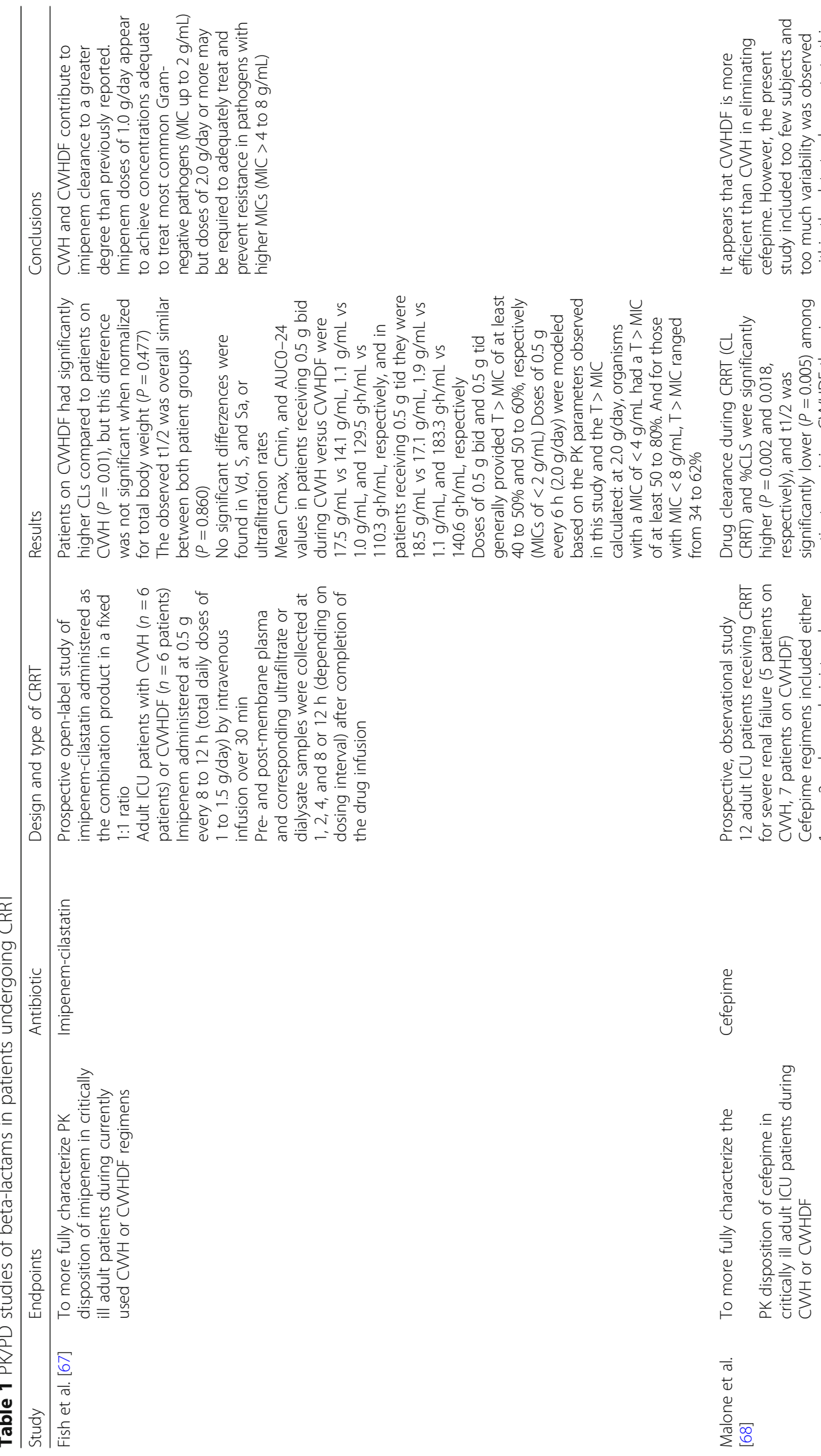




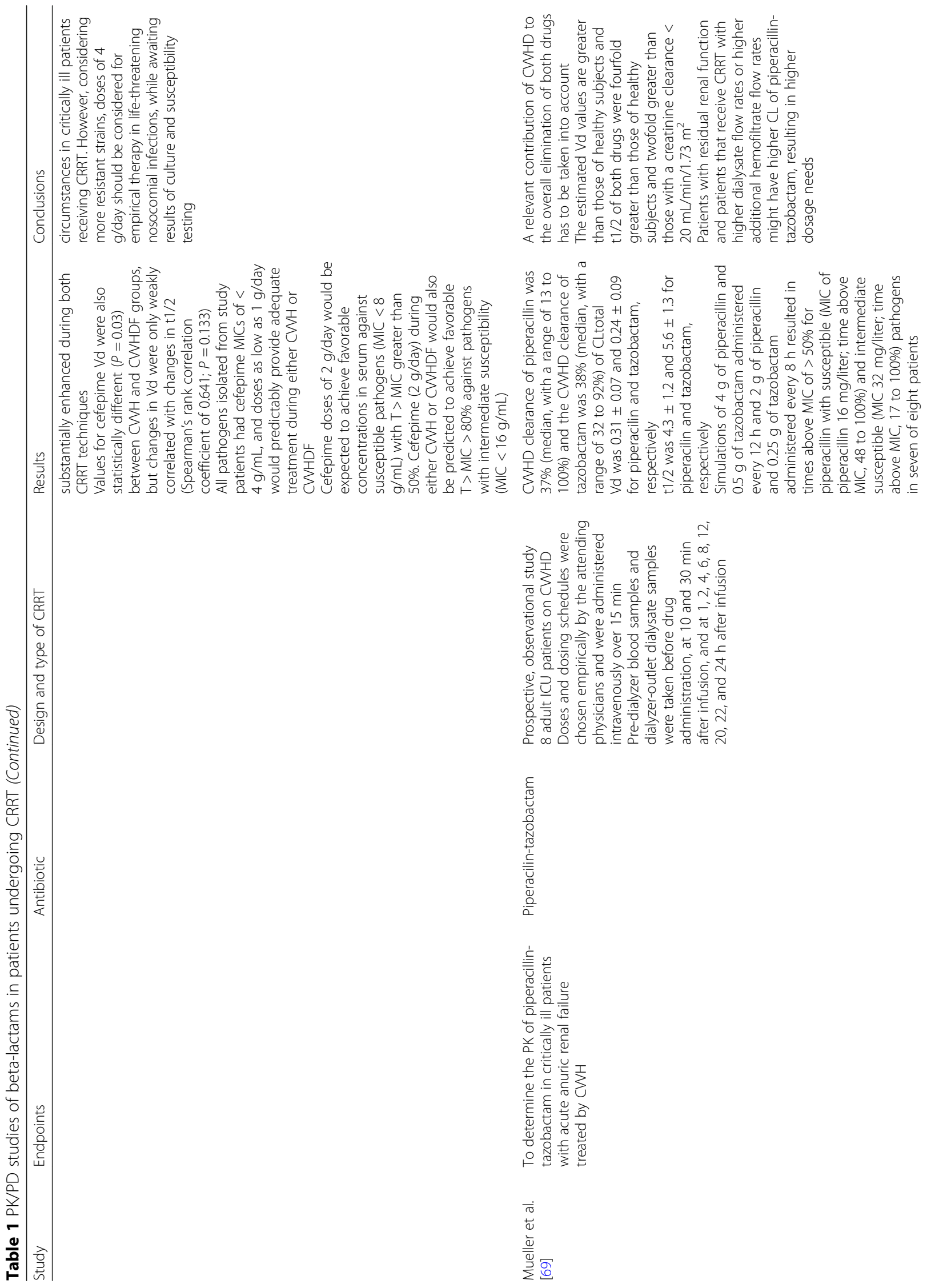




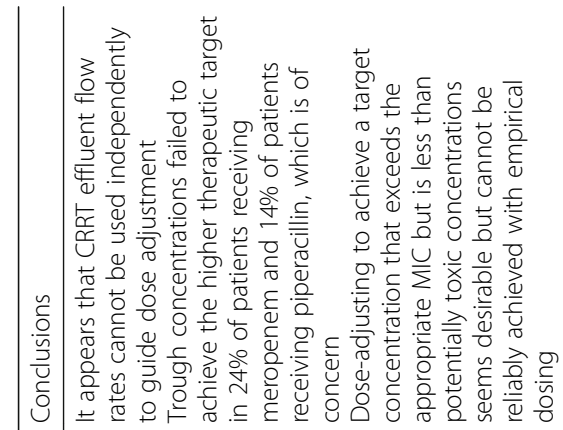

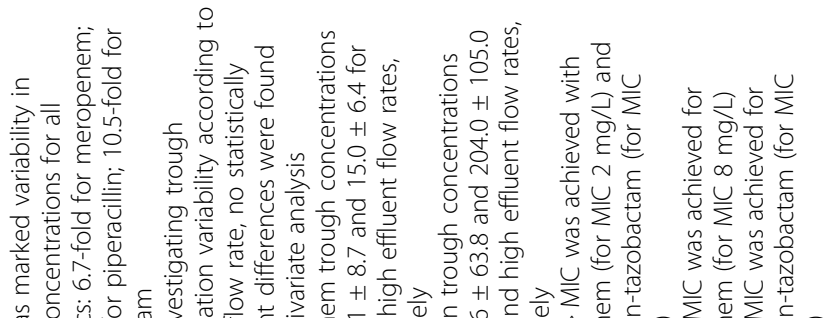

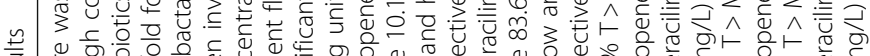

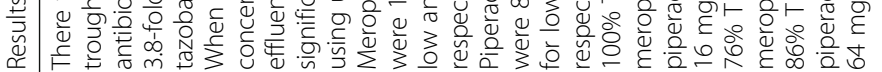

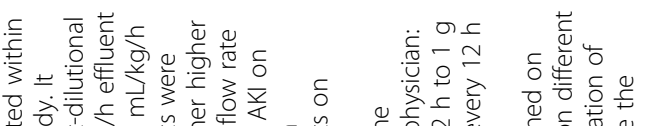

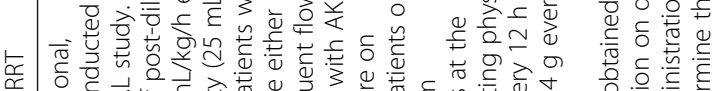

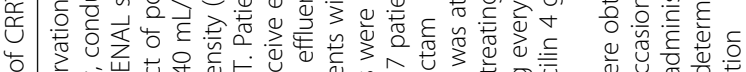

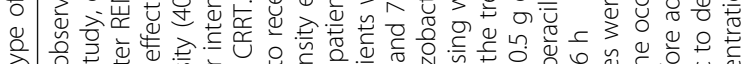

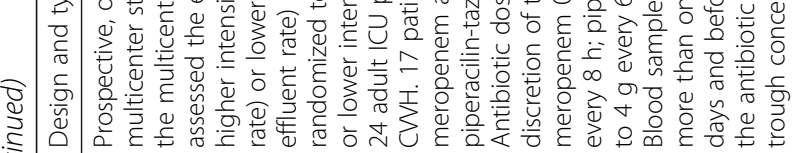

$\varepsilon$

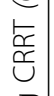

号

둥 $\frac{\pi}{8}$

ह

ปั)

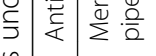

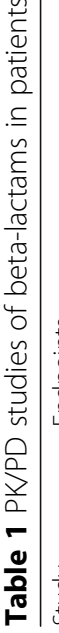

$\because \stackrel{4}{\cup}$

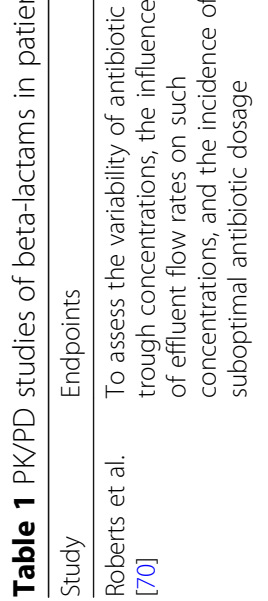

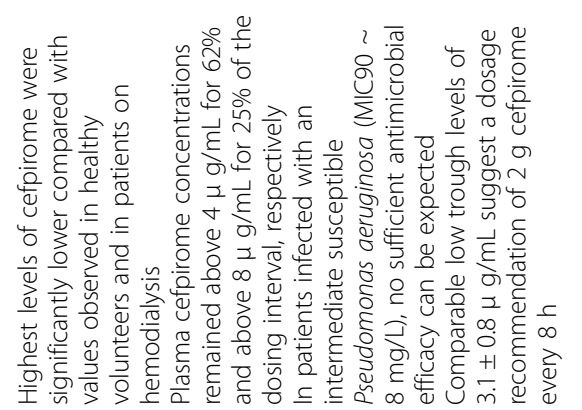

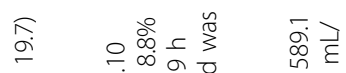

- $0 \infty+1$ in

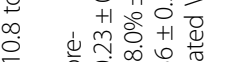

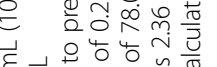

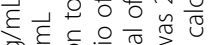

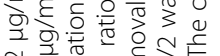

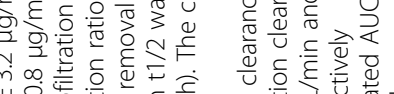

+10 造焉

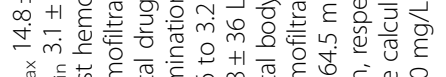

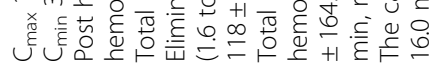

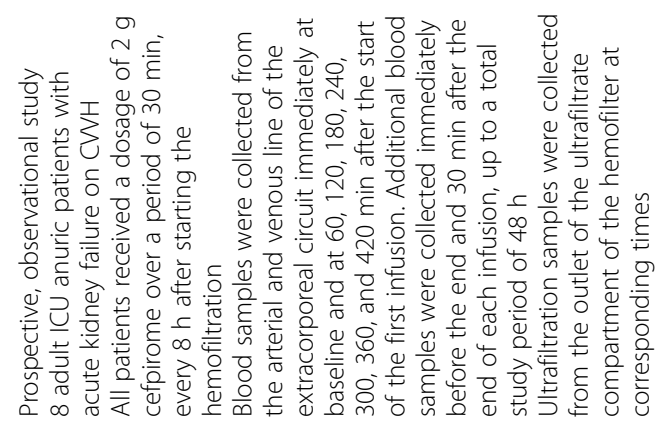

$\frac{\stackrel{\text { है }}{\frac{0}{0}}}{\frac{0}{U}}$

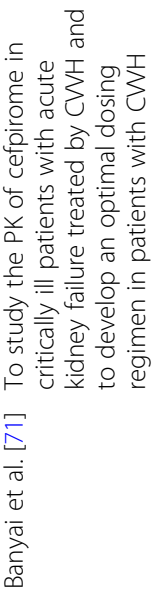




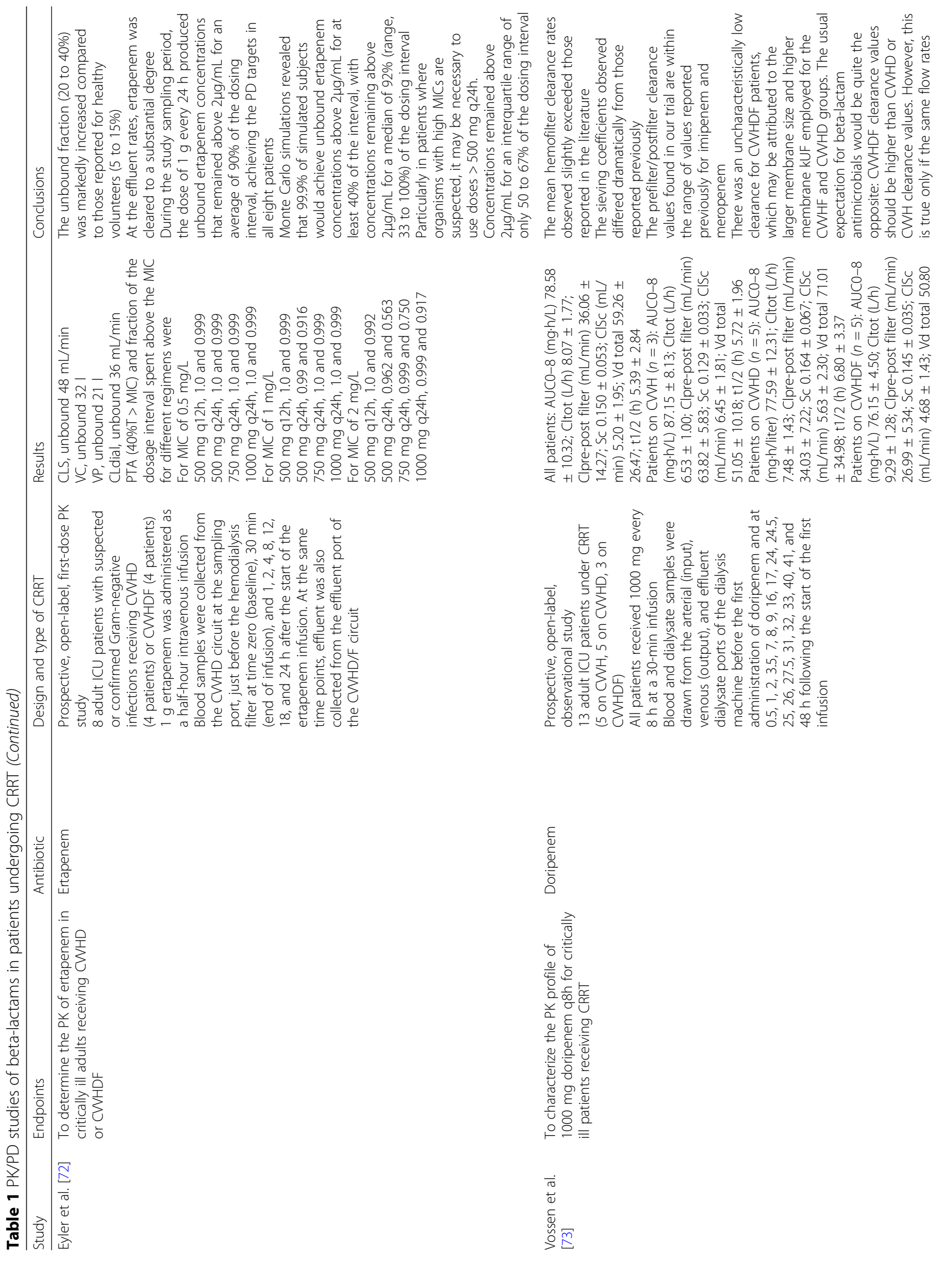




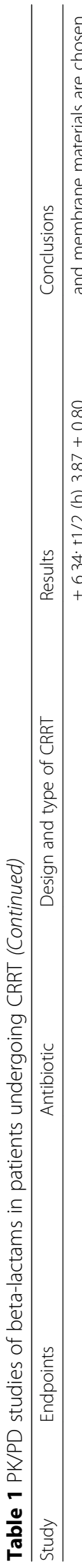

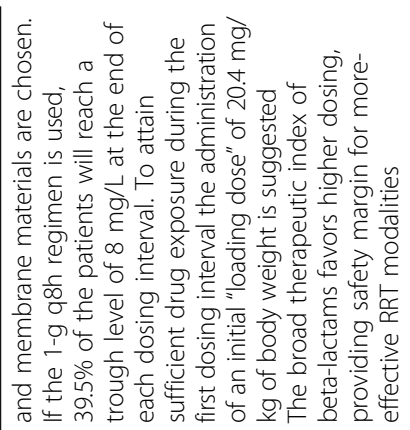

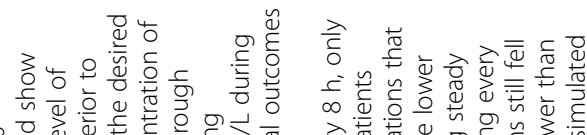

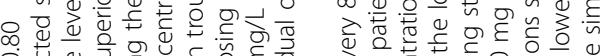

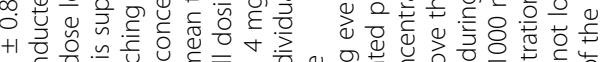

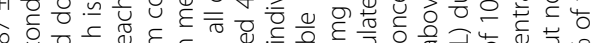

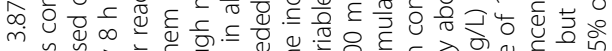

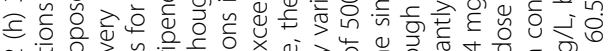

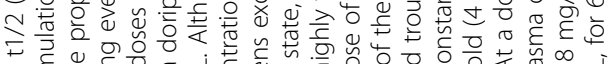

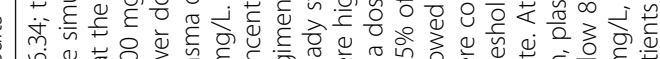
ชิ
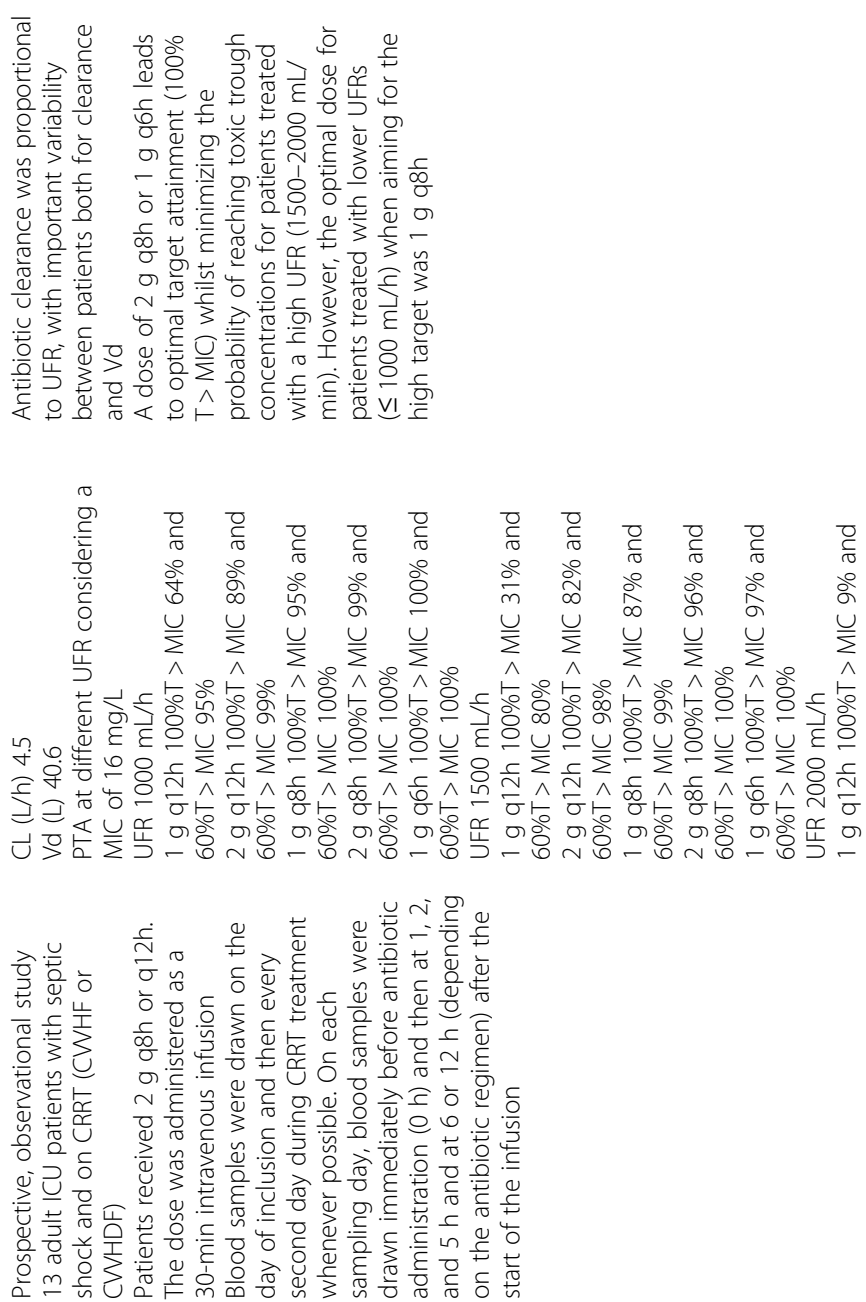

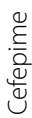

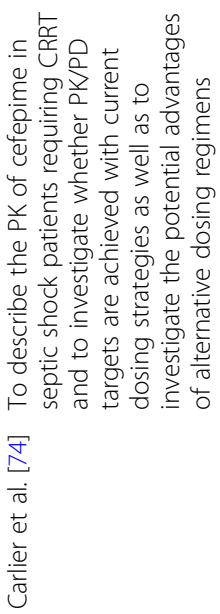




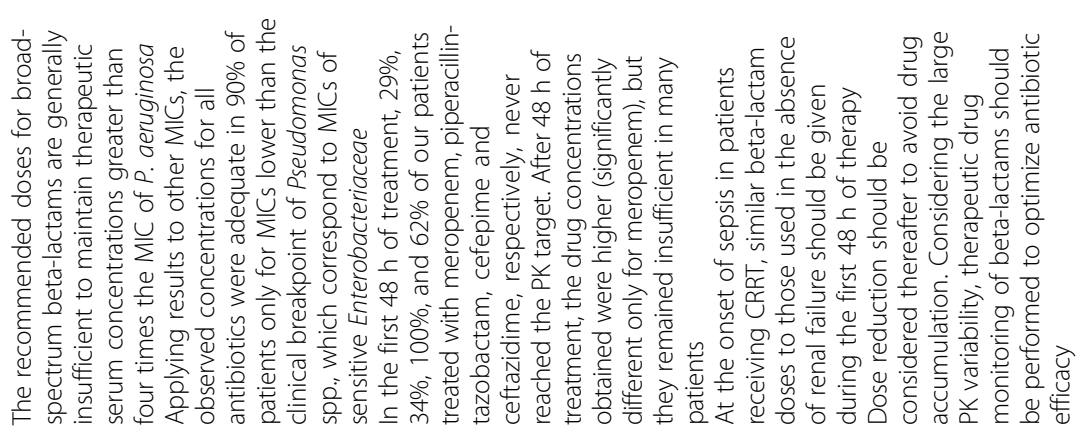

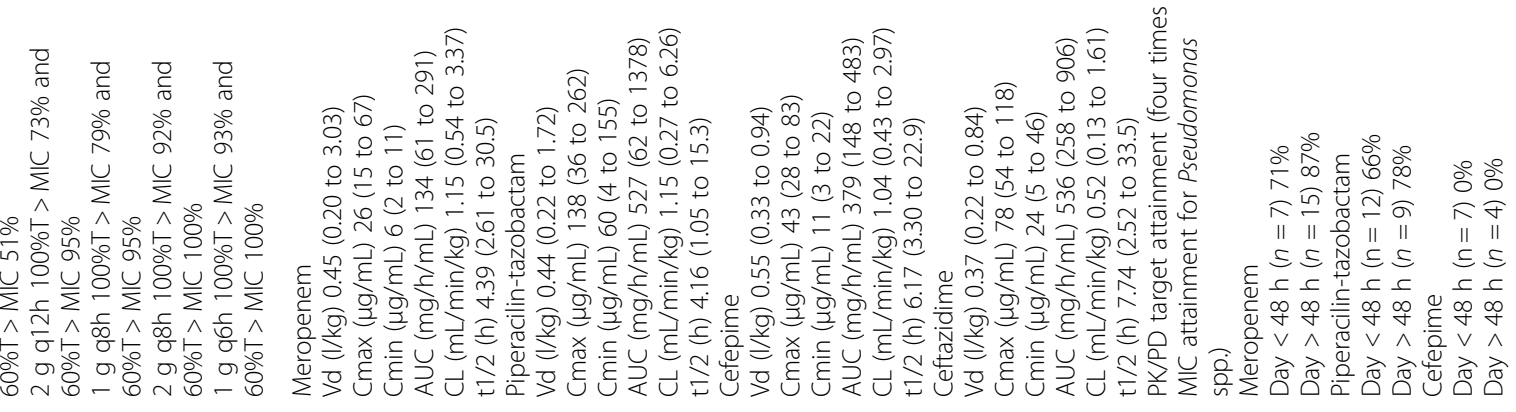

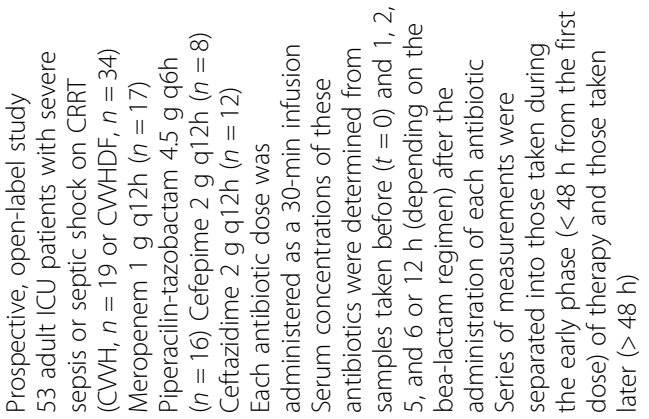

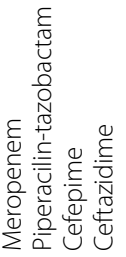

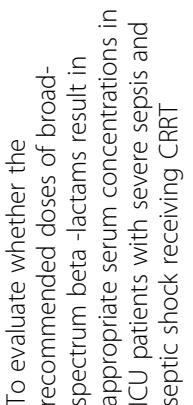

$\sqrt{n}$

迹 


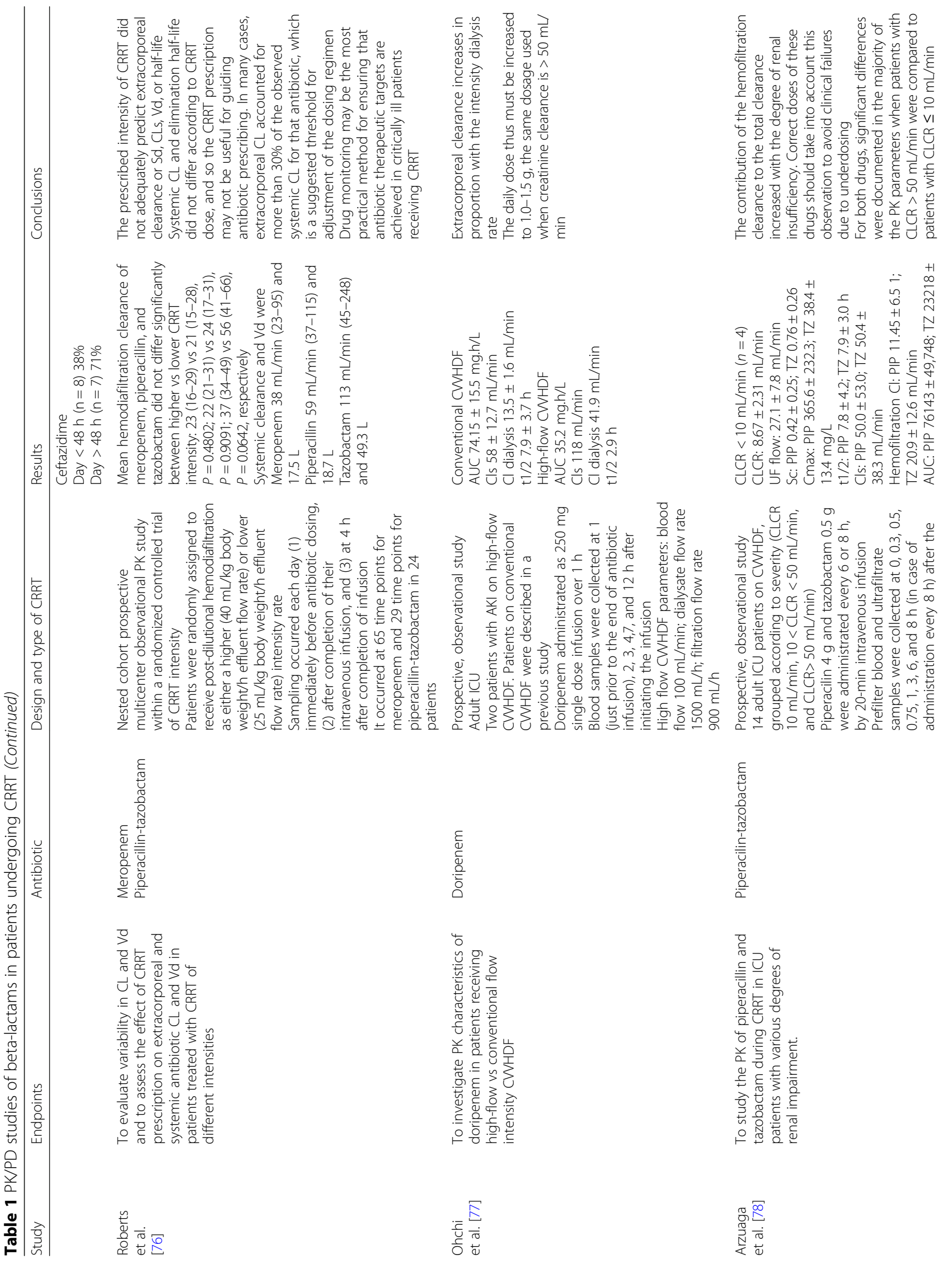




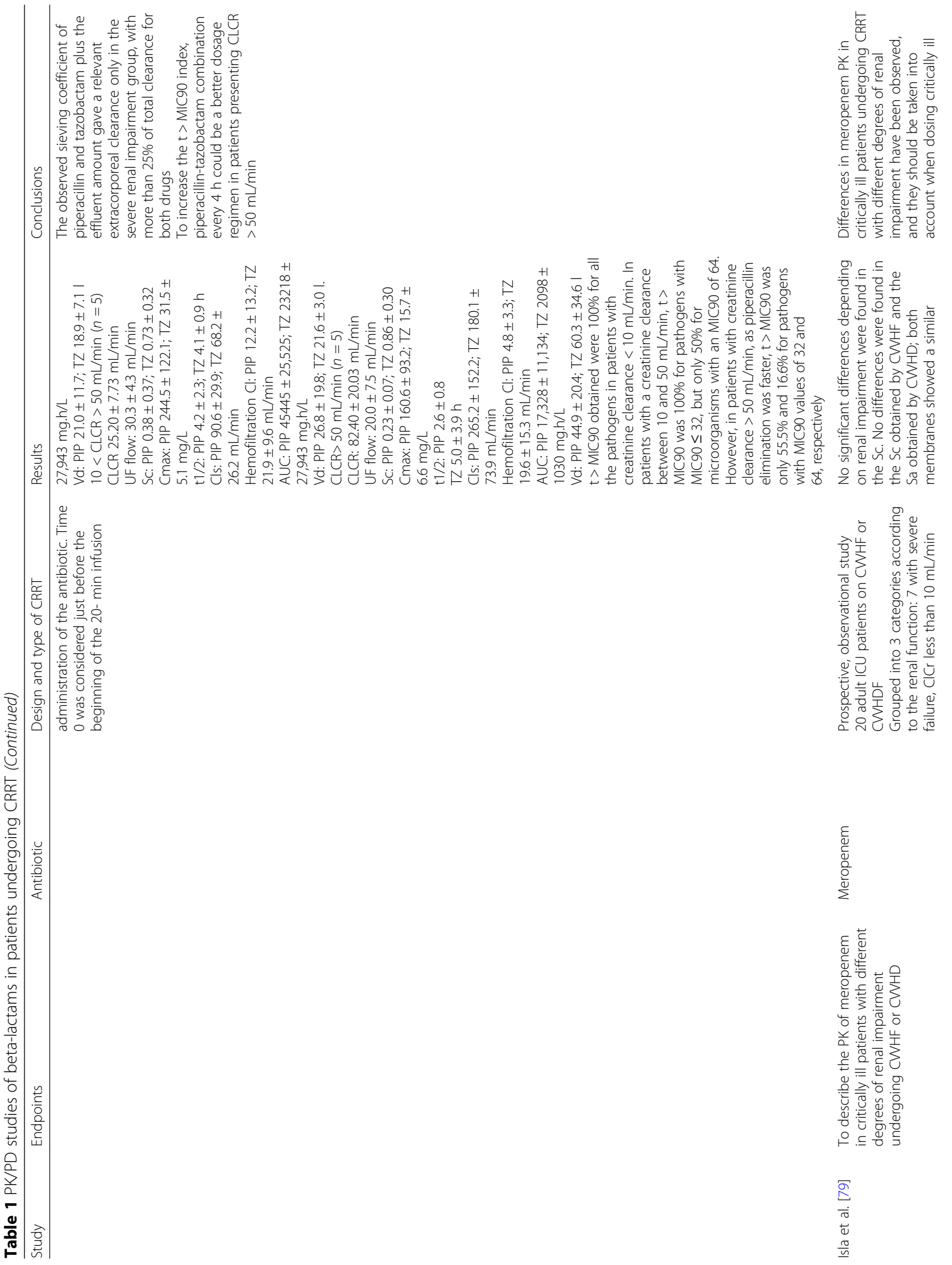




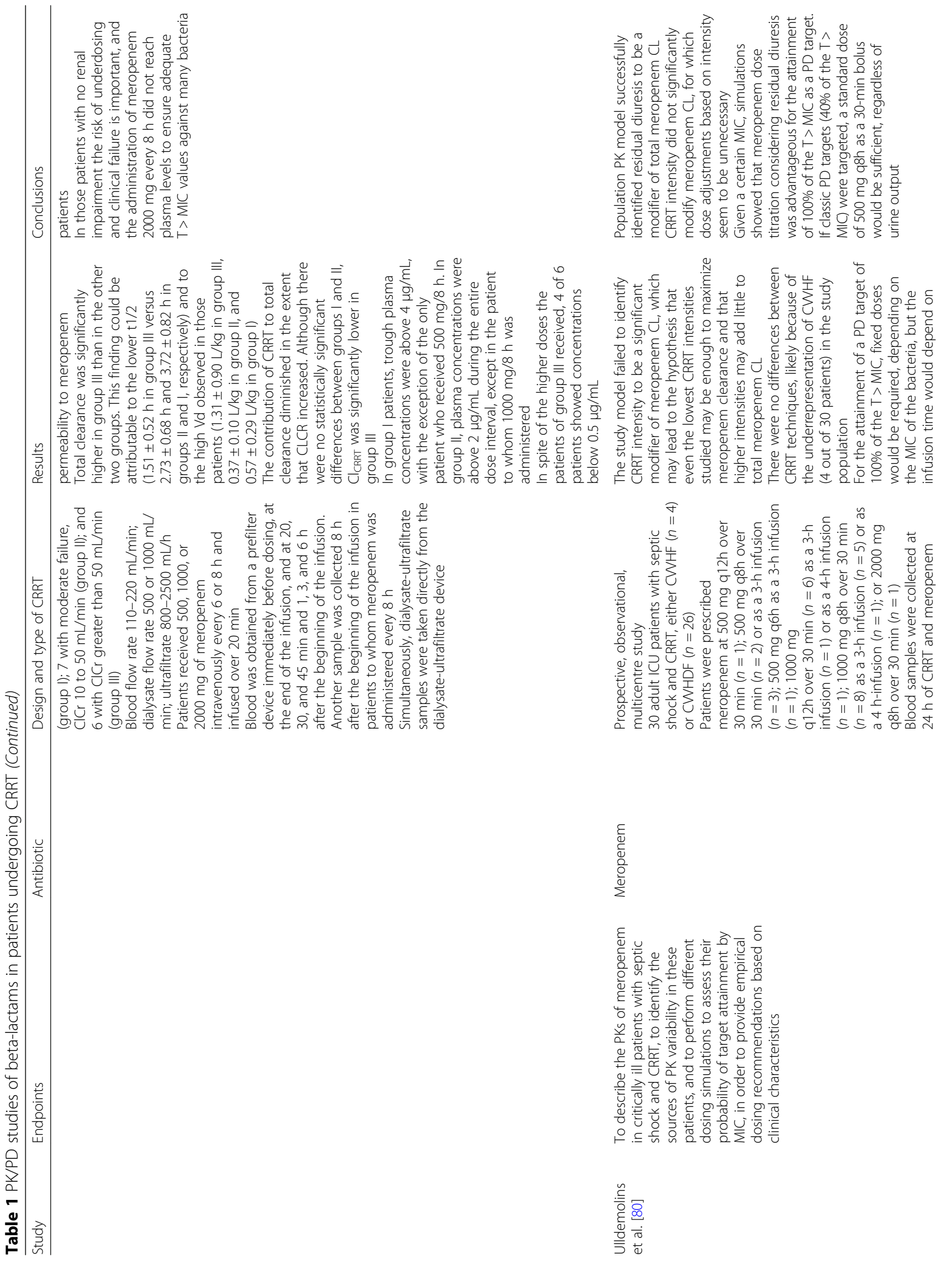




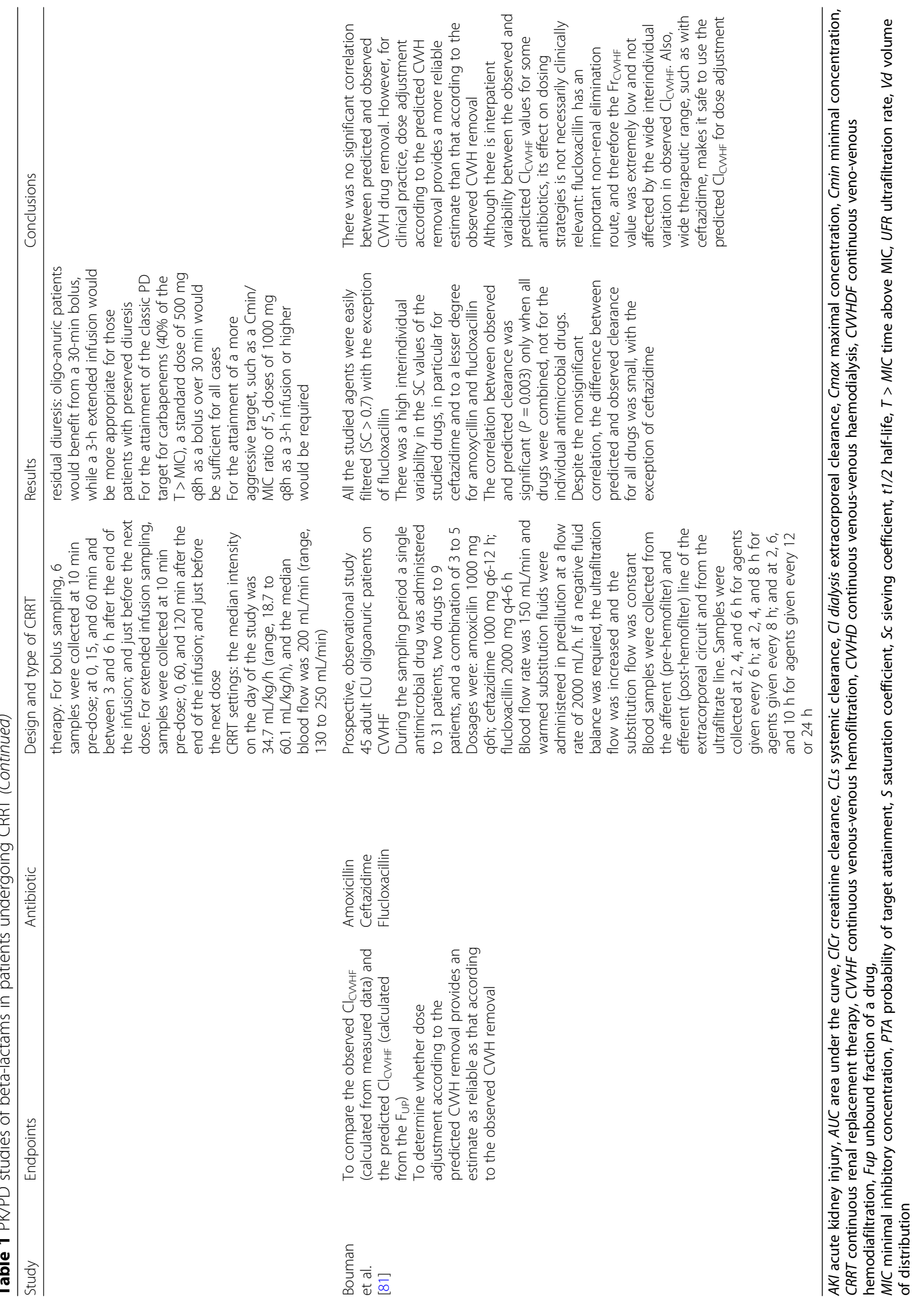




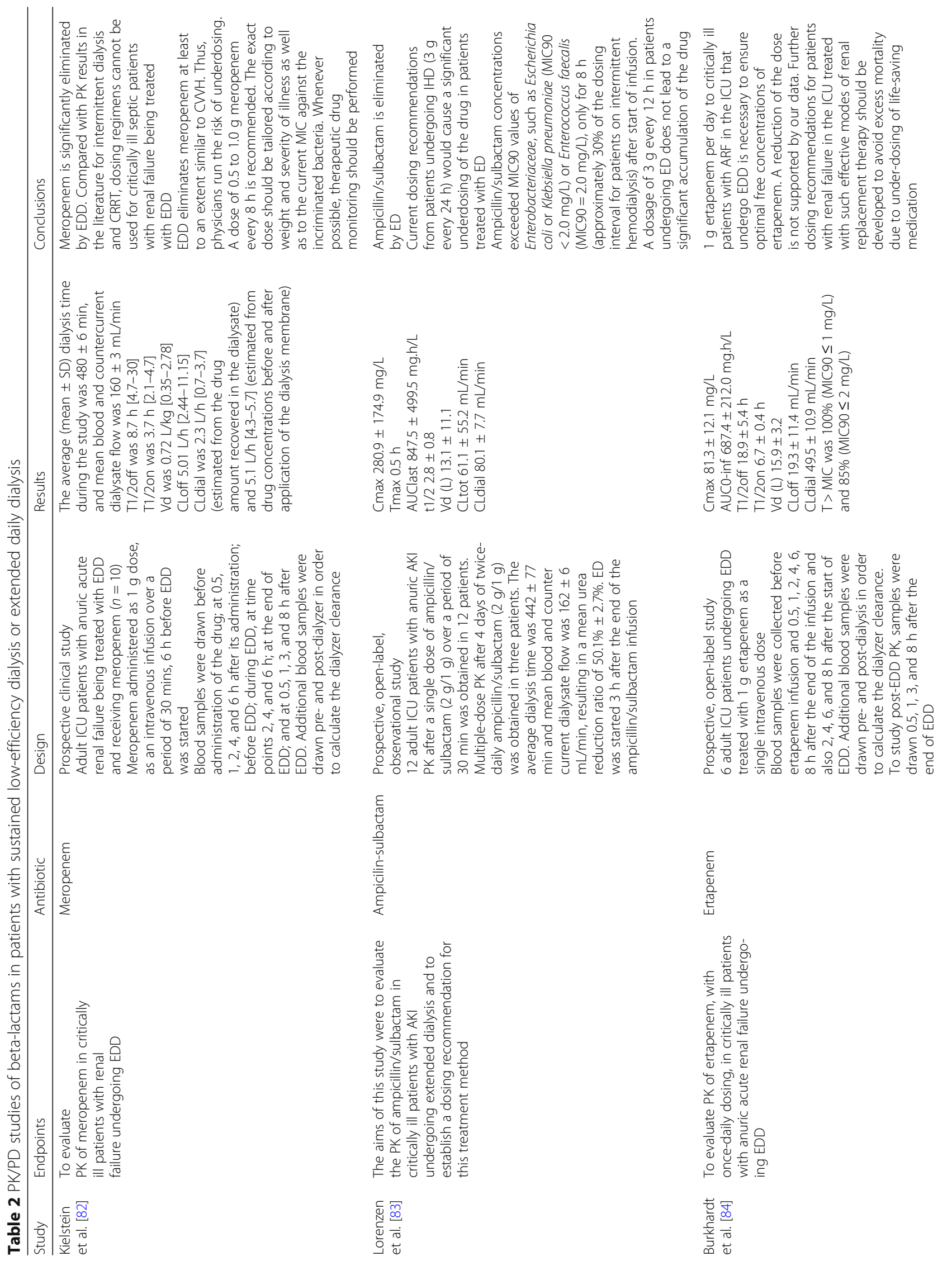




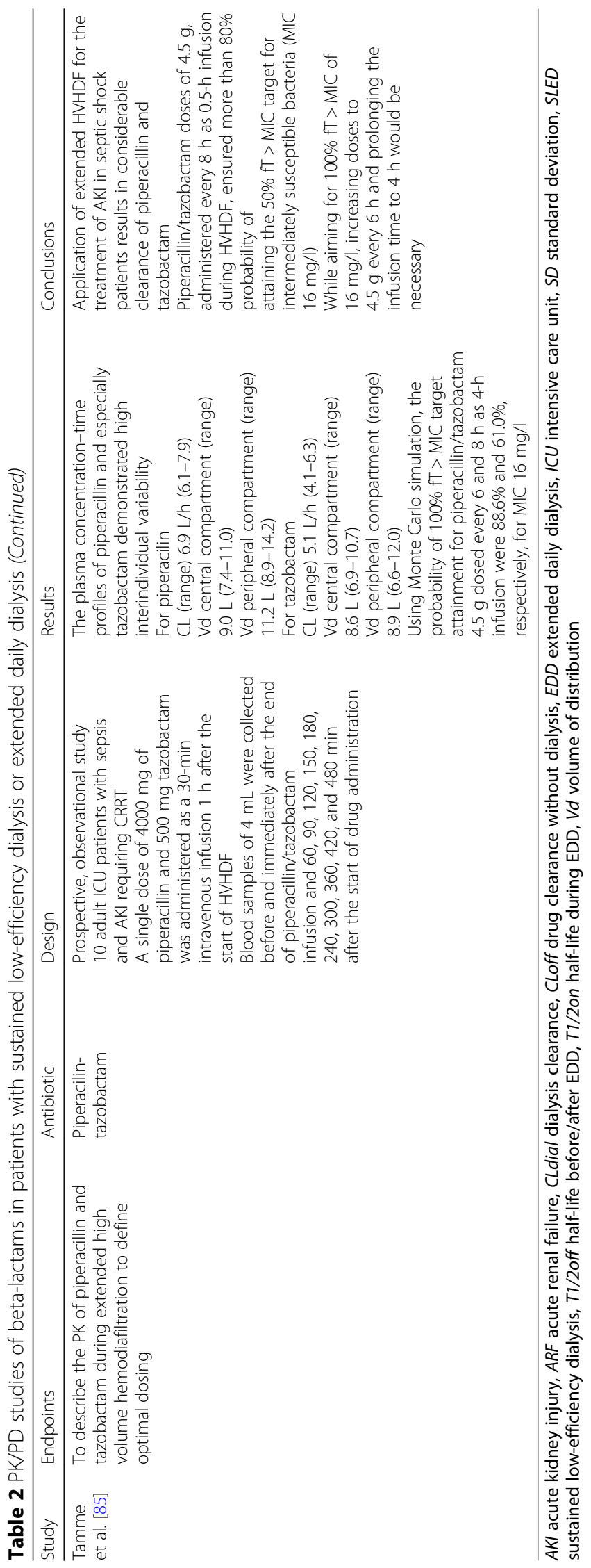




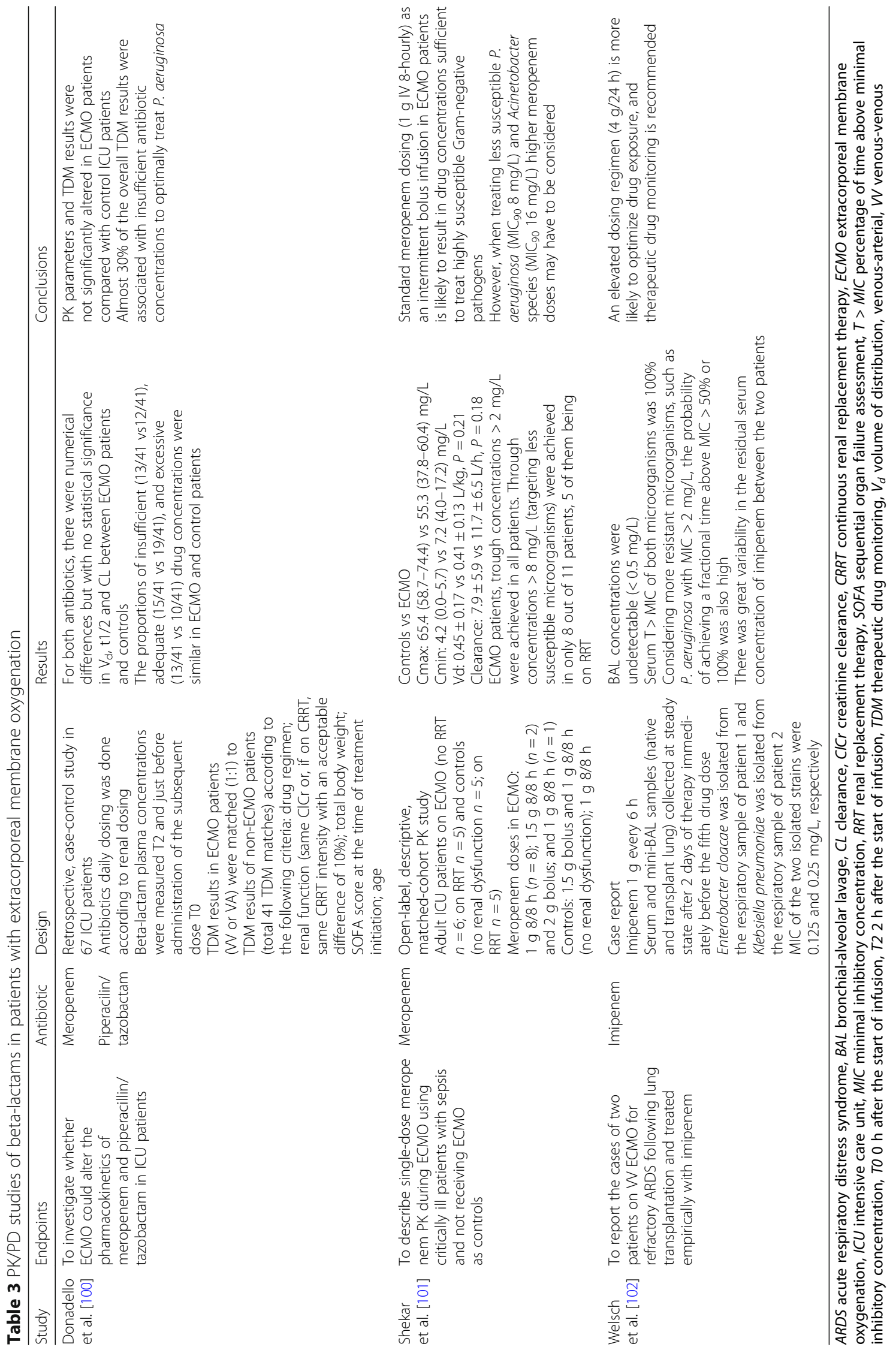


However results are conflicting concerning decreased mortality and bacteriological and clinical cure rates [144]. A sub-analysis from the DALI study compared intermittent bolus vs prolonged infusions of beta-lactams in patients with respiratory infection and concluded that patients receiving beta-lactams via prolonged infusion demonstrated significantly better 30-day survival [145].

Falagas et al. [114] conducted a meta-analysis of 14 studies comparing continuous and short-term infusion of carbapenems and piperacilin-tazobactam, involving 1229 patients. Mortality was lower among patients receiving extended or continuous infusion of carbapenems or piperacillin/tazobactam compared to those receiving short-term infusion (risk ratio (RR) 0.59, 95\% confidence interval (CI) 0.41-0.83). Patients with pneumonia who received extended or continuous infusion had lower mortality than those receiving short-term infusion (RR 0.50, 95\% CI 0.26-0.96) [114].

An interesting retrospective study by Huang et al. [120] reviewed 68 neurosurgical patients with post-operative intracranial infections treated with $4 \mathrm{~g}$ /day cefepime over $24 \mathrm{~h}$ as a continuous infusion (CI; $n=34)$ or $2 \mathrm{~g}$ every $12 \mathrm{~h}$ as intermittent infusion (II; $\mathrm{n}=34$ ). CI controlled the intracranial infection more rapidly and effectively than II (6.6 \pm 1.9 days vs $7.8 \pm 2.6$ days; $P=0.036$ ). PD targets were more achievable with $\mathrm{CI}$ : for plasma cefepime concentrations, the percentage $\mathrm{fT}>\mathrm{MIC}$ in the $\mathrm{CI}$ group was higher than in the II group (for MICs of $8 \mu \mathrm{g} / \mathrm{mL}, 100 \%$ vs $75 \%$, respectively). For cerebral spinal fluid (CSF) cefepime concentrations, the percentage $\mathrm{fT}>\mathrm{MIC}$ in the $\mathrm{CI}$ group was higher than in the II group (for MICs of $4 \mu \mathrm{g} / \mathrm{mL}$ and $8 \mu \mathrm{g} / \mathrm{mL}, 83.3 \%$ and $75 \%$ vs $25 \%$ and $0 \%$, respectively) [120].

De Waele et al. [27] reviewed 343 patients from 68 ICUs across ten countries and concluded that use of intermittent infusion was the most significant factor associated with target non-attainment, for both $50 \%$ and $100 \% \mathrm{fT}$ > MIC. Other risk factors for target non-attainment were $\mathrm{ClCr}$, recent surgery, and timing from initial antibiotic therapy and sampling. However, the type of infusion was such a significant covariate in the model that it eliminated the effects of other variables [27].

\section{Site of infection}

Usually drug concentrations in blood are used to determine PD parameters, such as percentage of time drug levels exceed the MIC and peak drug AUC/MIC level, due to the relative accessibility of this body fluid. Because infection usually occurs at extravascular sites, the use of drug concentrations in blood is only satisfactory if blood levels are an adequate surrogate for levels at the site of infection [13]. In septic shock, blood misdistribution in the microcirculation might decrease antibiotic concentration at the infection site [1].
Boyadjiev et al. [146] studied ertapenem penetration into muscle in mechanically ventilated patients and concluded that average muscle free-ertapenem concentrations were above the MIC values of targeted pathogens except in a few patients. Karjagin et al. [147] evaluated the PK/PD relations of meropenem in plasma and peritoneal fluid by microdialysis and showed that area under the concentration-time curve was lower in peritoneal fluid than in plasma, concluding that in patients with severe peritonitis associated with septic shock, a dosing regimen of $1 \mathrm{~g}$ infused over 20 min every $8 \mathrm{~h}$ is sufficient against susceptible bacteria, but not always against intermediately susceptible bacteria. Also, beta-lactam PK is variable between plasma and subcutaneous interstitial fluid in septic patients [148]. Thus, prediction of microbiological outcome based on concentrations in plasma results in overestimation of antimicrobial activity at the site of infection.

Special anatomic barriers (e.g., brain, eye, and prostate) can result in drug levels being much lower than free drug levels in plasma [13]. The combination of tight junctions and active transport systems that form the blood-brain barrier creates a substantial impediment to the penetration of most antibiotics into the CSF. However, the presence of inflammation within the meninges significantly alters the permeability of the blood-brain barrier, increasing CSF exposure for the majority of antibiotics [20]. For meningitis, CSF levels are appropriate for determination of PD parameters.

Very few studies have investigated PK/PD issues in the CSF (Table 4). Five case reports, one randomized clinical trial in a paediatric population, and three prospective observational studies found good probability of target attainment for susceptible strains but standard dosing may not be optimal for less susceptible strains. Prolonged and/or continuous infusion is of benefit in the attempt to achieve PD targets. No data regarding intermittent versus continuous CSF ventricular drainage were found and conceptually these two types of drainage may alter the beta-lactam PK profile.

There is very sparse data on possible surrogate central nervous system penetration factors for beta-lactams, so no conclusions can be made. We recommend to use higher than standard dosing, preferably with continuous or prolonged infusions, especially when treating less susceptible bacterial strains. Toxicity did not increase at increased doses. Finally, none of these studies addressed clinical outcome.

Though there are PK models of plasma concentrations of beta-lactams specifically for the critically ill population with pneumonia, it is suggested that epithelial lining fluid (ELF) concentrations are important determinants of efficacy of treatment of bacterial pneumonia. ELF-to-serum penetration ratios may vary widely among 


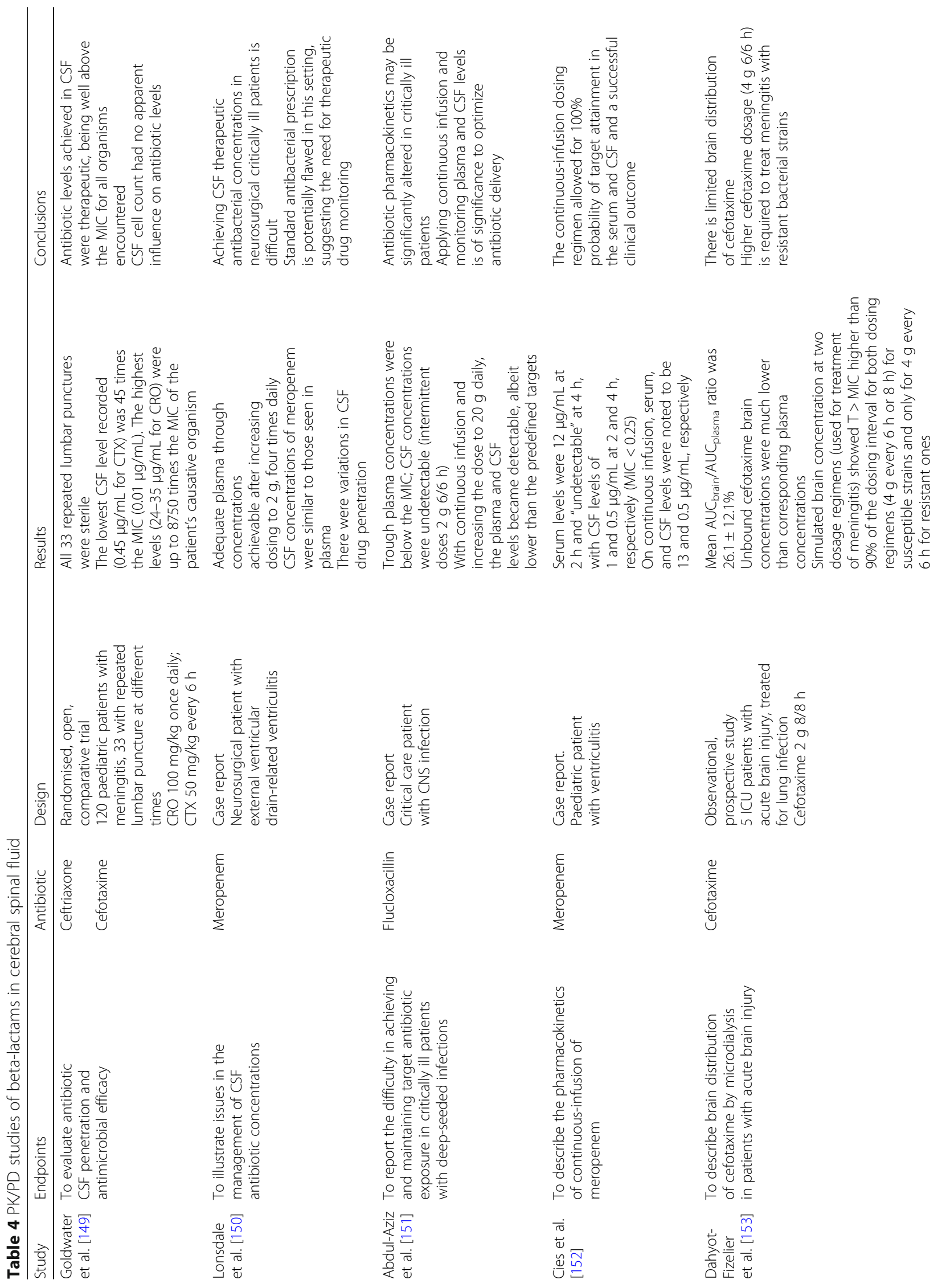




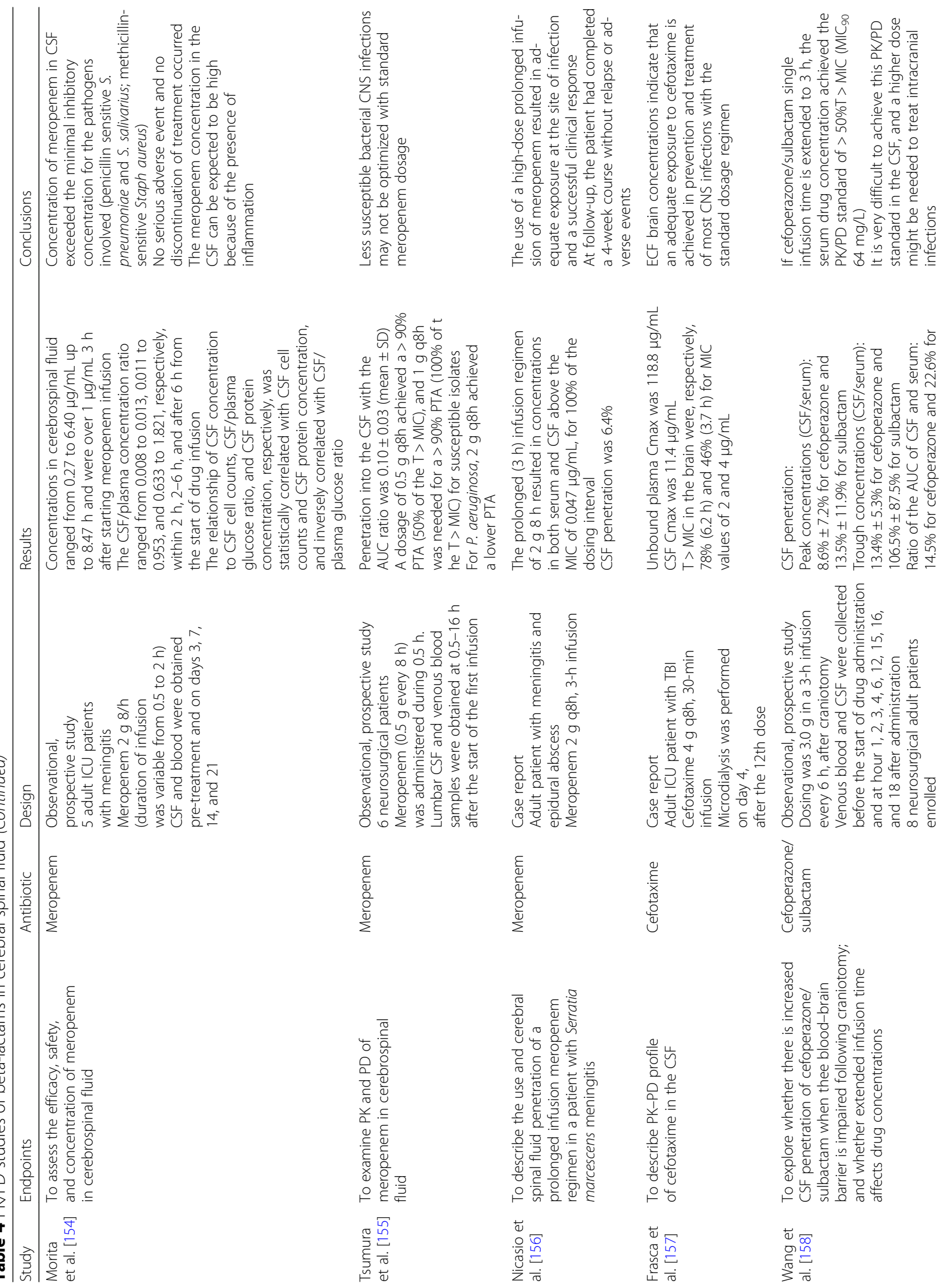


Veiga and Paiva Critical Care (2018) 22:233

Page 21 of 34

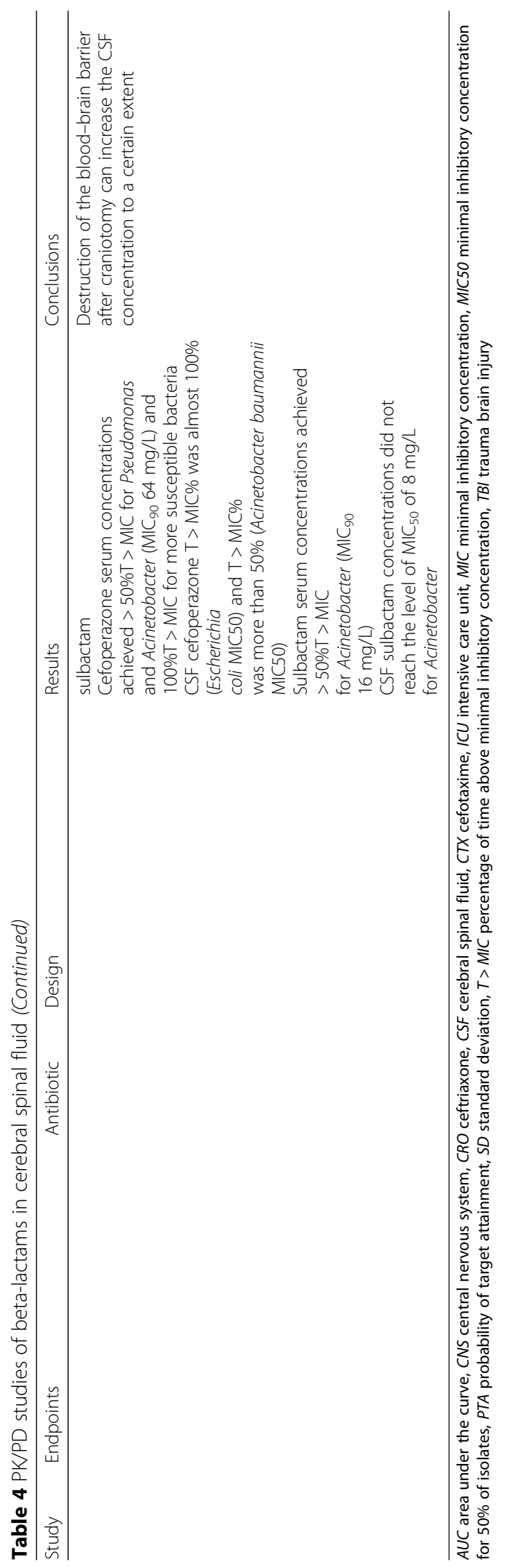


beta-lactams $[13,20,159]$. The impact of infection on their penetration into ELF in humans is unknown [159], though some reports state that ELF penetration increases in acute lung injury [160].

Only a few studies have investigated beta-lactam PK/PD issues in critically ill patients with pneumonia (Table 5) and in only seven of them were ELF drug concentrations measured. A standard dosage of beta-lactams derived from healthy patients' PK profiles may be insufficient for treatment of critically ill patients with pneumonia, especially when caused by multidrug-resistant pathogens. Continuous or prolonged infusions and higher than standard doses improve the PD profiles of these antibiotics. This is very important to achieve an adequate PD profile when treating less susceptible bacterial strains. Therapy drug monitoring would be extremely helpful in this setting.

\section{New beta-lactam drugs and beta-lactamase combinations}

Of great concern is the worldwide increase in the number of infections caused by Gram-negative multidrug-resistant bacteria. Treatment choices for these infections have been limited, especially for infections caused by bacteria that produce carbapenemases and/or extended-spectrum beta-lactamases.

Ceftolozane-tazobactam and ceftazidime-avibactam are 2 beta-lactams/beta-lactamase combinations with anti-Gram-negative bacteria activity that were recently approved for the treatment of complicated intra-abdominal infections, complicated urinary tract infections, and nosocomial pneumonia.

Ceftolozane is an oxyimino-aminothiazolyl cephalosporin with a pyrazole substituent at the 3-position side chain instead of the lighter pyridium present in ceftazidime. This heavier side chain provides improved steric hindrance to prevent hydrolysis mediated through AmpC beta-lactamases.

Ceftolozane-tazobactam combines a novel cephalosporin with an established beta-lactam beta-lactamase inhibitor, whereas ceftazidime-avibactam couples a well-known cephalosporin with a novel non-beta-lactam beta-lactamase inhibitor.

Both tazobactam and avibactam target the active site of serine beta-lactamases. Tazobactam, a beta-lactam sulfone, binds irreversibly to the active site of beta-lactamases and avibactam is a diazabicyclooctane non-beta-lactam that binds covalently and reversibly to beta-lactamases. This reversibility is a unique feature that allows avibactam to undergo recyclization to inactivate another beta-lactamase. The crucial advantage of avibactam is its ability to inhibit extended spectrum beta lactamases, AmpC beta-lactamases (as expressed in Pseudomonas aeruginosa and Enterobacteriaceae), and class A carbapenemases of the Klebsiella pneumoniae carbapenemase (KPC and OXA-48) family.
The pharmacokinetic and safety profiles of this antibiotic have been established in healthy adults and subjects with various degrees of renal function [170, 171]. The currently approved dosages for adult patients with an estimated $\mathrm{ClCr}>50 \mathrm{~mL} /$ minute are ceftolozane $1 \mathrm{~g}$ with tazobactam $500 \mathrm{mg}$ every $8 \mathrm{~h}$ and ceftazidime $2 \mathrm{~g}$ with avibactam $500 \mathrm{mg}$ every $8 \mathrm{~h}$ for complicated urinary tract infections and intra-abdominal infections [172] and ceftolozane $2 \mathrm{~g}$ with tazobactam $1 \mathrm{~g}$ every $8 \mathrm{~h}$ for nosocomial pneumonia [173].

However, data guiding its use in critically ill patients are currently sparse, being entirely derived from studies with very few patients and/or case reports.

Veillete et al. [174] presented PK data for ceftazidimeavibactam from two patients with bloodstream infections caused by carbapenemase (KPC)-producing K. pneumoniae; the patients had renal impairment and one of them was obese. In both patients half-lives were prolonged and Vd larger than predicted. They conclude that recommended doses and intervals may not be sufficient for obese patients with renal failure, especially for those infected with KPC-producing organisms [174].

Oliver et al. [175] evaluated the adequacy of extended-infusion ceftolozane-tazobactam to achieve target PK and PD goals in a critically ill patient with Pseudomonas aeruginosa pneumonia and septic shock on CVVH. A dosage of $1.5 \mathrm{~g}$ every $8 \mathrm{~h}$ (3-h infusion) was given. All estimated plasma-free drug concentrations achieved the PD goals and remained well above the isolated organism's MIC of $1.5 \mu \mathrm{g} / \mathrm{mL}$ and above the susceptibility breakpoint of $4 \mu \mathrm{g} / \mathrm{mL}$ throughout the dosing interval, although the authors could not comment on drug concentrations at the site of infection. The authors conclude that, given the lowest estimated free-drug concentration was fivefold greater than the susceptibility breakpoint, the estimated half-life of $28 \mathrm{~h}$ and the low extraction ratio observed, a lower total daily dose might be utilized and an extended infusion time may not be necessary for patients on CVVH [175].

Bremmer et al. [176] performed a PK analysis of intravenous ceftolozane-tazobactam 3 g every $8 \mathrm{~h}$ in a critically ill patient with $P$. aeruginosa pneumonia on CVVHDF. They concluded that, compared with a patient with normal renal function, this patient had decreased ceftolozane clearance. A ceftolozane-tazobactam dosage of $1.5 \mathrm{~g}$ every $8 \mathrm{~h}$ should adequately achieve a desired drug concentration above the minimum inhibitory concentration of $8 \mu \mathrm{g} / \mathrm{mL}$ for the treatment of pneumonia [176].

Stokem et al. reported the successful treatment with ceftolozane-tazobactam $3 \mathrm{~g}$ every $12 \mathrm{~h}$ for a pulmonary exacerbation in a 35-year-old female post-lung transplant, with cystic fibrosis, malnutrition, chronic kidney disease, and multi-drug resistant $P$. aeruginosa infection. Optimal time above MIC (estimated 100\% time above 


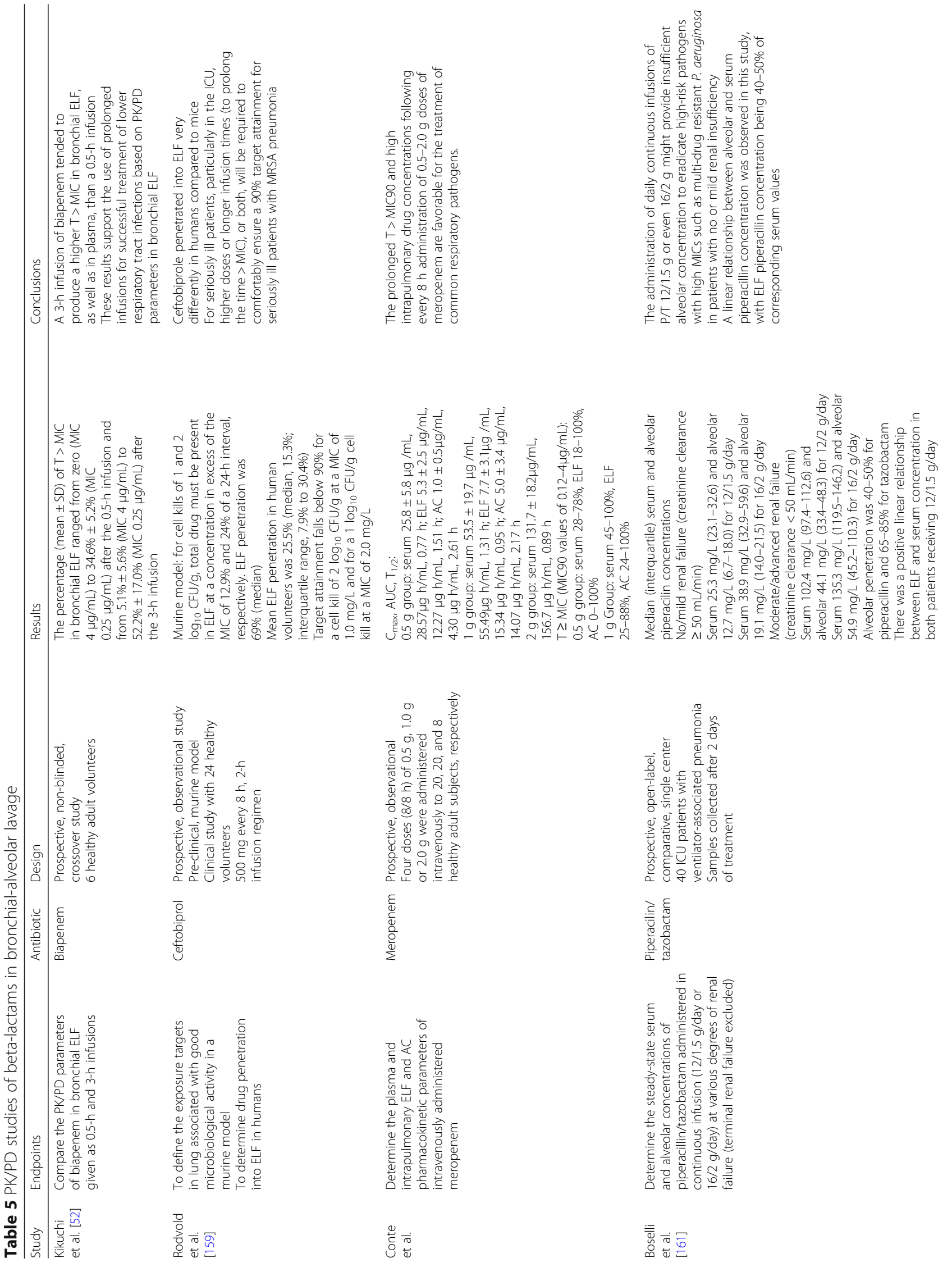




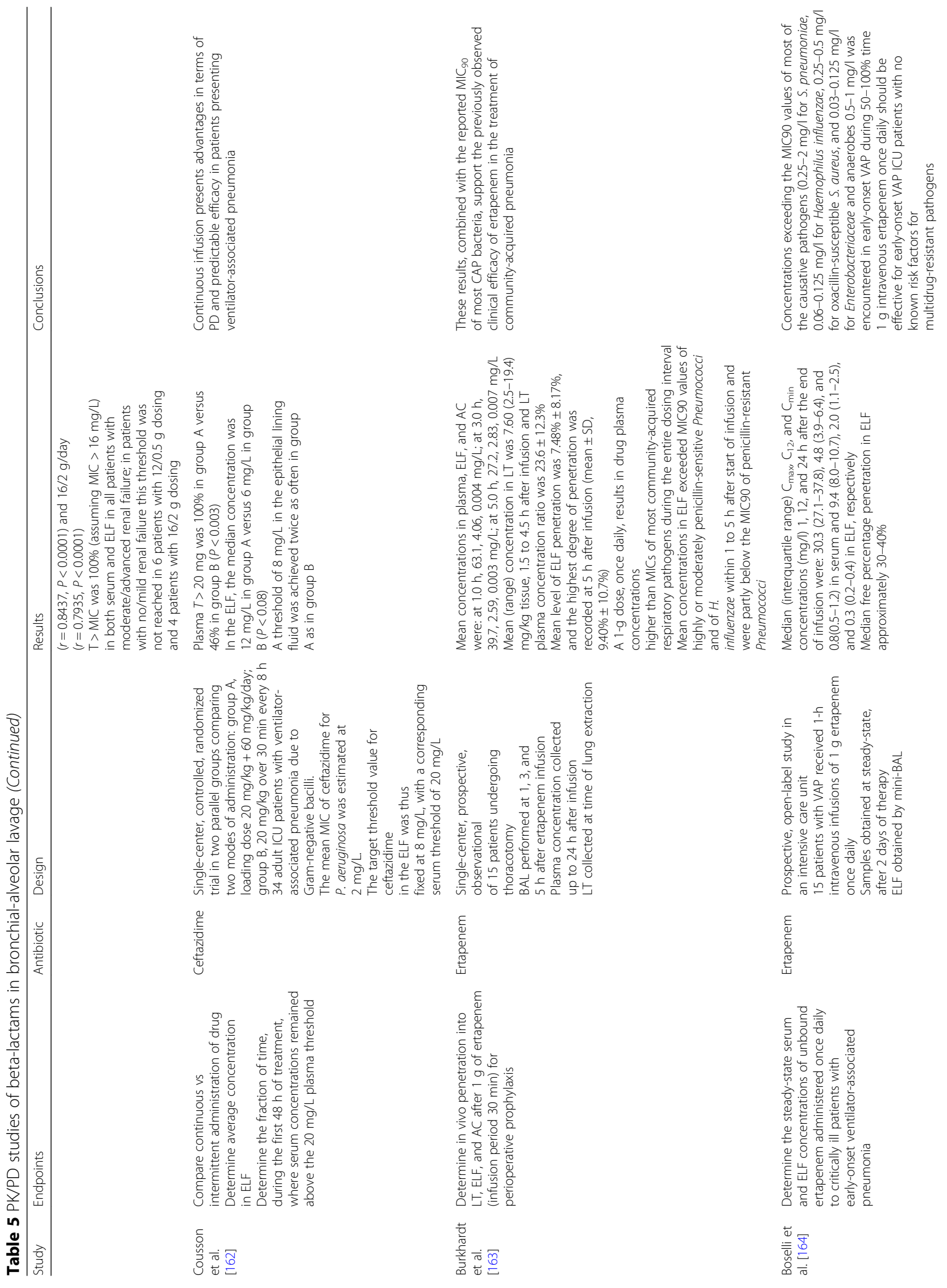




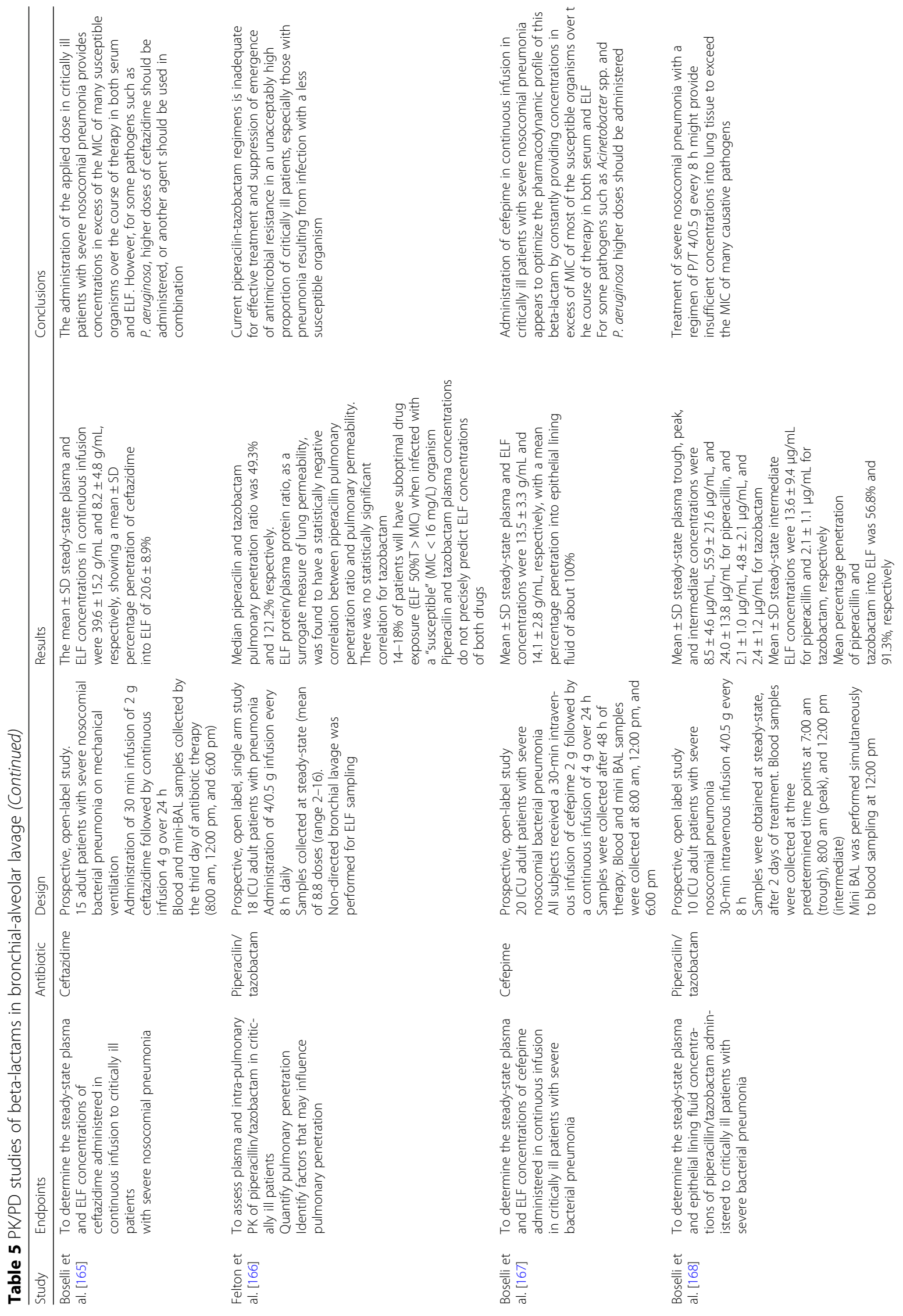




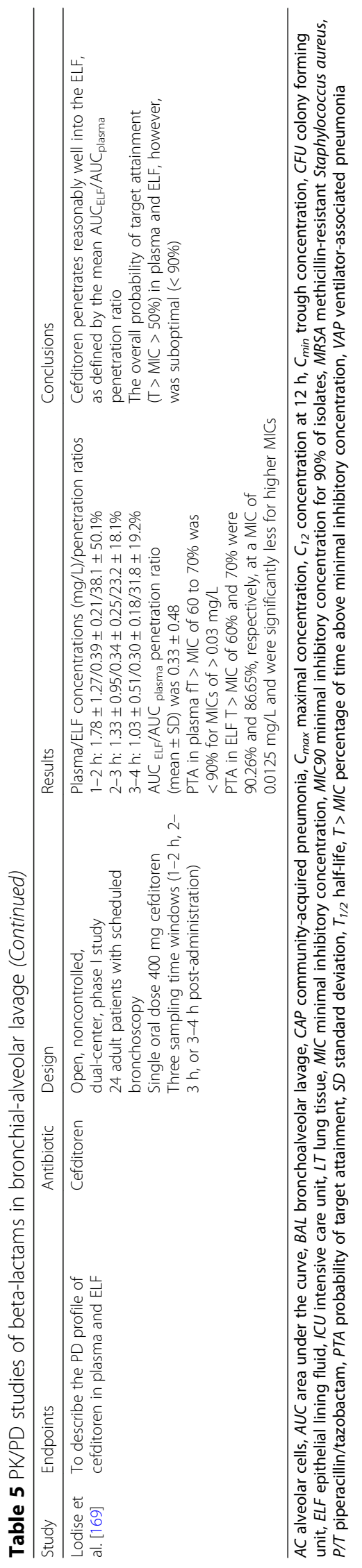


MIC of ceftolozane achieved against both isolates was 2 and $0.5 \mu \mathrm{g} / \mathrm{mL}$ ) was likely attained at the dose and frequency provided in this case [177].

\section{Toxicity}

Beta-lactams are generally considered to have a high safety window with relatively few adverse effects, even when high doses are used [15]. Neurotoxicity is the most reported serious adverse effect of beta-lactams. Benzylpenicillin, cefepime, ceftazidime, and imipenem are considered to be the high-risk beta-lactams for neurotoxicity. Renal impairment, excess doses and/or concentrations, age, and a prior history of neurological disorders are known to be predisposing factors [2, 178-184].

Other adverse effects are found in a few case reports: acute renal failure [185] and electrolyte disorders [186]; severe intravascular haemolysis [187, 188]; extreme thrombocytosis [189]; severe thrombocytopenia [190193]; leukopenia [194]; delayed-type hypersensitivity [195]; anaphylactic shock [196]; and severe cutaneous reactions [197].

\section{Therapeutic dose monitoring}

Several studies reported high PK variability of beta-lactams in sepsis/septic shock, both in different patients and in the same patient over time. In critically ill patients, hydrophilic and moderately lipophilic antimicrobials, being at higher risk of daily PK variations, should be more closely monitored and their dosages should be streamlined according to the underlying diseases in order to prevent under- or overexposure $[2,11]$.

Therapeutic drug monitoring (TDM) has been instituted for aminoglycosides and glycopeptides to reduce the rate of toxicity. However, because of the safety profile of beta-lactams, TDM was thought unnecessary for these drugs. In line with PK changes in critically ill patients, insufficient PD target attainment with beta-lactams has been reported in these patients, especially those with hypoalbuminemia, altered renal function, and low susceptibility bacterial strain infections [2, 35, 42, 198]. The challenges in achieving 'optimal' drug concentrations in the critically ill suggest beta-lactam TDM as a useful strategy to optimize drug exposure [199].

The TDM approach could be particularly useful in a certain group of critically ill patients in whom achieving target concentrations is more difficult, such as those with highly resistant bacterial strains, obese patients, immunocompromised patients, those undergoing renal-replacement therapies, and patients with augmented renal clearance [2, 198, 200, 201].

Though there are PK models to estimate antibiotic concentrations over a range of creatinine clearance $(\mathrm{CrCl})$ and on renal replacement therapy [67, 202-205], the use of $\mathrm{CrCl}$ as a tool to optimize beta-lactam dosing may not be reliable; although $\mathrm{CrCl}$ was significantly correlated with concentrations and clearance of broad-spectrum beta-lactams, changes in $\mathrm{CrCl}$ and $\mathrm{RRT}$ parameters do not reliably predict variations in drug PK/PD. In this setting, routine TDM should be considered to adapt beta-lactam doses [206].

Daily TDM of beta-lactams with dose adaptation in critically ill patients improves PD target attainment [207, 208]. Case reports have shown that TDM improved clinical outcome [209], but the clinical efficacy of using drug levels to achieve adequate concentrations had never been properly evaluated $[1,35,210,211]$ and there are reports concerning cost-effectiveness [111].

Facing poor implementation in beta-lactam TDM, Delattre et al. [212] proposed a predictive PK performance between an aminoglycoside and a beta-lactam. Due to physicochemical and PK similarities between aminoglycosides and beta-lactams, optimization of the beta-lactam dosage could be reached without any beta-lactam measurements, using TDM-related data of an aminoglycoside. The study aimed to characterize the PK of four beta-lactams (piperacillin, ceftazidime, cefepime, and meropenem) at the first dose in 88 critically ill septic patients co-medicated with amikacin, and to confirm the predictive performance of amikacin data on these $\mathrm{PK}$, on a larger patient cohort, using a nonlinear mixed-effects modeling approach. There was a significant relationship between the exposure to amikacin and to beta-lactams. The population model presented was able to guide dosage adjustments for piperacillin, ceftazidime, cefepime, and meropenem during the early phase of severe sepsis in critically ill patients, using renal biomarkers or TDM-related aminoglycoside data [212].

\section{Conclusions}

The duration of infusion of beta-lactams has been shown to influence their $\mathrm{fT}>\mathrm{MIC}$ and an improved PD profile of beta-lactams may be obtained by longer exposure with more frequent dosing, extended infusions, or continuous infusions. This is particularly relevant in the critically ill patient, as $\mathrm{Vd}$ and $\mathrm{ClCr}$ are often increased, namely in the early phase of systemic hyperinflammatory states, promoting the risk of antibiotic underdosing.

The use of extracorporeal support techniques, either for renal replacement or ECMO, may further contribute to this problem and consequently concentrations below those expected are often found for beta-lactams. Given the heterogeneity of extracorporeal support therapy modes, it is difficult to suggest a specific dosage, but we recommend not to reduce dosage since no drug accumulation was found in the available literature and to use continuous or prolonged infusions to achieve the adequate PD profiles necessary to successfully treat infections caused by less susceptible strains. 
More studies are needed to define optimal dosing of new beta-lactams and new beta-lactam/beta-lactamase combinations, which are increasingly important to effectively treat multidrug-resistant bacterial strains, namely in patients on extracorporeal support therapy and with difficult-to-treat sites of infection.

Although, it is not currently a clinical routine in most hospitals and its clinical efficacy has not yet been properly evaluated, a beta-lactam TDM approach with daily dose adaptation, allowing personalized antibiotic dosing, should be particularly useful in critically ill patients in whom achieving target concentrations is more difficult, such as obese patients, the immunocompromised, patients with augmented renal clearance, those undergoing extracorporeal support therapy, or those infected with highly resistant bacterial strains. Studies comparing TDM- versus non-TDM-based beta-lactam regimens should be promoted.

However, infection usually occurs at extravascular sites and prediction of outcome based on antibiotic plasma concentrations may result in overestimation of antimicrobial activity at the site of infection. Very few studies have investigated $\mathrm{PK} / \mathrm{PD}$ issues concerning special anatomic barriers like the brain and lung, but most suggest that standard ICU dosing for beta-lactams may be insufficient for low susceptibility/high MIC pathogens in these sites. Therefore, although no studies have assessed clinical outcome, we recommend using higher than standard dosing, preferably with continuous or prolonged infusions, when treating severe infections caused by less susceptible bacterial strains at these sites, as PD profiles may improve and toxicity does not seems to increase.

\section{Abbreviations \\ AKI: Aacute kidney injury; AUC: Aarea under the curve; C: Concentration; CFU: Colony-forming units; Cl: Continuous infusion; Cl: Clearance; CICr: Creatinine clearance; CNS: Central nervous system; CRRT: Continuous renal replacement therapy; CSF: Cerebral spinal fluid; CWHD: Continuous venous-venous hemodialysis; CWHDF: Continuous venous-venous hemodia- filtration; CWHF: Continuous venous-venous hemofiltration; ECMO: Extracorporeal membrane oxygenation; EDD: Extended daily dialysis; ELF: Epithelial lining fluid; ICU: Intensive care unit; II: Intermittent infusion; KPC: Carbapenemase producing Klebsiella; MBC: Minimal bactericidal concentration; MIC: Minimum inhibitory concentration; PAE: Post-antibiotic effect; PD: Pharmacodynamics; PK: Pharmacokinetics; PTA: Probability of target attainment; RRT: Renal replacement therapy; SLED: Sustained low- efficiency dialysis; TDM: Therapeutic drug monitoring; VAP: Ventilator associated pneumonia; Vd: Volume of distribution}

\section{Availability of data and materials}

All data generated or analyzed during this study are included in this published article (see bibliography).

\section{Authors' contributions}

RV and JAP made substantial contributions to conception and design, acquisition of data, and analysis and interpretation of data; were involved in drafting the manuscript or revising it critically for important intellectual content; gave final approval of the version to be published; agreed to be accountable for all aspects of the work in ensuring that questions related to the accuracy or integrity of any part of the work are appropriately investigated and resolved.
Ethics approval and consent to participate

Not applicable.

\section{Consent for publication}

Not applicable.

Competing interests

The authors declare that they have no competing interests.

\section{Publisher's Note}

Springer Nature remains neutral with regard to jurisdictional claims in published maps and institutional affiliations.

\section{Author details}

${ }^{1}$ Centro Hospitalar São João, EPE - Intensive Care Department, Porto, Portugal. ${ }^{2}$ Faculty of Medicine - University of Porto, Porto, Portugal. ${ }^{3}$ Grupo Infeção e Sepsis, Porto, Portugal.

Received: 23 April 2018 Accepted: 8 August 2018

Published online: 24 September 2018

\section{References}

1. Gonçalves-Pereira J, Póvoa P. Antibiotics in critically ill patients: a systematic review of the pharmacokinetics of b-lactams. Crit Care. 2011;15(5):R206.

2. Sinnollareddy MJ, Roberts MS, Lipman J, Roberts JA. Beta-lactam pharmacokinetics and pharmacodynamics in critically ill patients and strategies for dose optimization: A structured review. Clin Exp Pharmacol Physiol. 2012;39:489-96.

3. Puskarich MA, Trzeciak S, Shapiro NI, Arnold RC, Horton JM, Studnek JR, Kline JA, Jones AE, On behalf of the Emergency Medicine Shock Research Network. Association between timing of antibiotic administration and mortality from septic shock in patients treated with a quantitative resuscitation protocol. Crit Care Med. 2011;39:2066-71.

4. Kumar A, Roberts D, Wood KE, Light B, Parrillo JE, Sharma S, Suppes R, Feinstein D, Zanotti S, Taiberg L, Gurka D, Kumar A, Cheang M. Duration of hypotension before initiation of effective antimicrobial therapy is the critical determinant of survival in human septic shock. Crit Care Med. 2006;34: 1589-96.

5. Roberts JA, Paul SK, Akova M, Bassetti M, De Waele JJ, Dimopoulos G, Kaukonen KM, Koulenti D, Martin C, Montravers P, Rello J, Rhodes A, Starr T, Wallis SC, Lipman J, for the DALI Study. DALI: defining antibiotic levels in intensive care unit patients: are current $\beta$-lactam antibiotic doses sufficient for critically ill patients? Clin Infect Dis. 2014; https://doi.org/10.1093/cid/ciu027.

6. Zilberberg MD, Shorr AF, Micek ST, Vazquez-Guillamet C, Kollef MH. Multidrug resistance, inappropriate initial antibiotic therapy and mortality in Gram-negative severe sepsis and septic shock: a retrospective cohort study. Crit Care. 2014;18:596.

7. Bloos F, Ruddel H, Thomas-Ruddel D, Schwarzkopf D, Pausch C, Harbarth S, Schreiber T, Grundling M, Marshall J, Simon P, Levy MM, Weiss M, Weyland A, Gerlach H, Schurholz T, Engel C, Matthaus-Kramer C, Scheer C, Bach F, Riessen R, Poidinger B, Dey K, Weiler N, Meier-Helmann A, Haberle HH, Wobker G, Kaisers UX, Reinhart K. Effect of a multifaceted educational intervention for anti-infectious measures on sepsis mortality: a cluster randomized trial. Intensive Care Med. 2017;43:1602-12.

8. Ryoo SM, Kim WY, Sohn CH, Seo DW, Koh JW, Oh BJ, Lim KS. Prognostic value of timing of antibiotic administration in patients with septic shock treated with early quantitative resuscitation in emergency departments. Am J Med Sci. 2015;349:328-33.

9. Vilella AL, Seifert CF. Timing and appropriateness of initial antibiotic therapy in newly presenting septic patients. Am J Emerg Med. 2014;32:7-13.

10. Rhodes A, Evans LE, Alhazzani W, Levy MM, Antonelli M, Ferrer R, Kumar A, Sevransky JE, Sprung CL, Nunnally ME, Rochwerg B, Rubenfeld GD, Angus DC, Annane D, Beale RJ, Bellinghan GJ, Bernard GR, Chiche JD, Coopersmith C, De Backer DP, French CJ, Fujishima S, Gerlach H, Hidalgo JL, Hollenberg SM, Jones AE, Karnad DR, Kleinpell RM, Koh Y, Lisboa TC, Machado FR, Marini JJ, Marshall JC, Mazuski JE, Mclntyre LA, McLean AS, Mehta S, Moreno RP, Myburgh J, Navalesi P, Nishida O, Osborn TM, Perner A, Plunkett CM, Ranieri M, Schorr CA, Seckel MA, Seymour CW, Shieh L, Shukri KA, Simpson SQ, Singer M, Thompson BT, Townsend SR, Van der Poll T, Vincent JL, Wiersinga WJ, Zimmerman JL, Dellinger RP. Surviving Sepsis Campaign: 
International guidelines for management of sepsis and septic shock: 2016. Intensive Care Med. 2017:43:304-77.

11. Bloos F, Rüdde H, Thomas-Rüddel D, Schwarzkopf D, Pausch C, Harbarth S, Schreiber T, Gründling M, Marshall J, Simon P, Levy MM, Weiss M, Weyland A, Gerlach H, Schürholz T, Engel C, Matth C, Scheer C, Bach F, Riessen R, Poidinger B, Dey K, Weiler N, Meier-Hellmann A, Häberle HH, Wöbker G, Kaisers UX, Reinhart K for the MEDUSA study group. Effect of a multifaceted educational intervention for anti-infectious measures on sepsis mortality: a cluster randomized trial. Intensive Care Med. 2017;43:1602-12.

12. Pea F, Viale P, FurlanutM. Antimicrobial therapy in critically ill patients. A review of pathophysiological conditions responsible for altered disposition and pharmacokinetic variability. Clin Pharmacokinet. 2005;44:1009-34.

13. Levison ME. Pharmacodynamics of antimicrobial drugs. Infect Dis Clin N Am. 2004;18:451-65.

14. Roberts JA, Lipman J. Pharmacokinetic issues for antibiotics in the critically ill patient. Crit Care Med. 2009;37:840-51.

15. McKinnon PS, Paladino JA, Schentag JJ. Evaluation of area under the inhibitory curve (AUIC) and time above the minimum inhibitory concentration (T>MIC) as predictors of outcome for cefepime and ceftazidime in serious bacterial infections. Int J Antimicrob Agents. 2008;31:345-51.

16. Roos JF, Lipman J, Kirkpatrick CMJ. Population pharmacokinetics and pharmacodynamics of cefpirome in critically ill patients against Gramnegative bacteria. Intensive Care Med. 2007;33:781-8.

17. Sime BK, Roberts MS, Warner MS, Hahn U, Robertson TA, Yeend S, Phay A, Lehman S, Lipman J, Peake SL, Roberts JA. Altered pharmacokinetics of piperacillin in febrile neutropenic patients with haematological malignancy. Antimicrob Agents Chemother. 2014;5:3533-7.

18. Taccone FS, Cotton F, Vincent JL, Jacobs F. Optimal meropenem concentrations to treat multidrug-resistant Pseudomonas aeruginosa septic shock. Antimicrob Agents Chemother. 2012;56:2129-31.

19. Ashley WS, Allen N, Rafferty KD, Fish DN, Toschlog E, Newell M, Waibel B. Pharmacokinetic analysis of piperacillin administered with tazobactam in critically ill, Morbidly Obese Surgical Patients. Pharmacotherapy. 2014;34: 28-35.

20. Onufrak NJ, Forrest A, Gonzalez D. Pharmacokinetic and pharmacodynamic principles of anti-infective dosing. Clin Ther. 2016;8:1930-47.

21. Syamhanin A, Li JX, Wallis SC, Rudd M, Jarrett P, Paterson DL, Lipman J, Udy AA, Roberts JA. Pharmacokinetics of meropenem and piperacillin in critically ill patients with indwelling surgical drains. Int J Antimicrob Agents. 2013;42:90-3.

22. Brink AJ, Richards JA, Schillack V, Kiem S, Schentag J. Pharmacokinetics of once-daily dosing of ertapenem in critically ill patients with severe sepsis. Int J Antimicrob Agents. 2009;33:432-6.

23. Roberts JA, Udy AA, Jarret P, Wallis SC, Hope WW, Sharma R, Kirkpatrick CMJ, Kruger PS, Roberts MS, Lipman J. Plasma and target-site subcutaneous tissue population pharmacokinetics and dosing simulations of cefazolin in posttrauma critically ill patients. J Antimicrob Chemother. 2015;70:1495-502.

24. Jeon S, Han S, Lee J, Hong T, Paek J, Woo H, Yima DS. Population pharmacokinetic analysis of piperacillin in burn patients. Antimicrob Agents Chemother. 2014;58:3744-51.

25. Carlier M, Noe M, Roberts JA, Stove V, Verstraete AG, Lipman J, De Waele JJ. Population pharmacokinetics and dosing simulations of cefuroxime in critically ill patients: non-standard dosing approaches are required to achieve therapeutic exposures. J Antimicrob Chemother. 2014;69:2797-803.

26. Coufignall C, Pajot O, Laouénan C, Burdet C, Foucrier A, Wolff M, ArmandLefevre L, Mentré F, Massias L. Population pharmacokinetics of imipenem in critically ill patients with suspected ventilator-associated pneumonia and evaluation of dosage regimens. Br J Clin Pharmacol. 2014;78:1022-34.

27. De Waele JJ, Lipman J, Akova M, Bassetti M, Dimopoulos G, Kaukonen M, Koulenti D, Martin C, Montravers P, Rello J, Rhodes A, Udy AA, Starr T, Wallis SC, Roberts JA. Risk factors for target non-attainment during empirical treatment with b-lactam antibiotics in critically ill patients. Intensive Care Med. 2014:40:1340-51.

28. Meyer B, Traunmueller F, Bojic A, Locker G, Schmid R, Winkler S, Thalhammer $F$. Single-dose pharmacokinetics of cefodizime in critically ill elderly patients. Int J Antimicrob Agents. 2006;27:335-8.

29. Blot SI, Pea F, Lipman J. The effect of pathophysiology on pharmacokinetics in the critically ill patient - Concepts appraised by the example of antimicrobial agents. Adv Drug Deliv Rev. 2014;77:3-11.

30. Joynt JM, Lipman J, Gomersall CD, Young RJ, Wong ELY, Gin T. The pharmacokinetics of once-daily dosing of ceftriaxone in critically ill patients. J Antimicrob Chemother. 2001;47:421-9.
31. Dalley AJ, Lipman J, Deans R, Vankatesh B, Rudd M, Roberts MS, Cross SE. Tissue accumulation of cephalothin in burns: a comparative study by microdialysis of subcutaneous interstitial fluid cephalothin concentrations in burn patients and healthy volunteers. Antimicrob Agents Chemother. 2009:53:210-5.

32. Dalley AJ, Deans R, Lipman J, Venkatesh B, Rudd M, Roberts MS, Cross SE. Unbound cephalothin pharmacokinetics in adult burn patients are related to the elapsed time after injury. Antimicrob Agents Chemother. 2009;53: 5303-5.

33. Gonçalves-Pereira J, Silva NE, Mateus A, Pinho C, Póvoa P. Assessment of pharmacokinetic changes of meropenem during therapy in septic critically ill patients. BMC Pharmacol Toxicol. 2014;15:21.

34. Conil JM, Georges B, Ravat F, Ruiz S, Seguin T, Metsu D, Fourcade O, Saivin S. Ceftazidime dosage recommendations in burn patients: from a population pharmacokinetic approach to clinical practice via Monte Carlo simulations. Clin Ther. 2013;35:1603-12.

35. Isla A, Rodriguez-Gascón A, Trocóniz IF, Bueno L, Solinís MA, Maynar J, Sanchéz-Izquierdo JÁ, Pedraz JL. Population pharmacokinetics of meropenem in critically ill patients undergoing continuous renal replacement therapy. Clin Pharmacokinet. 2008;47:173-80.

36. Udy AA, Roberts JA, Lipman J. Clinical implications of antibiotic pharmacokinetic principles in the critically ill. Intensive Care Med. 2013;39:2070-82.

37. Carlier M, Carrette S, Stove V, Verstraete AG. Does consistent piperacillin dosing result in consistent therapeutic concentrations in critically ill patients? A longitudinal study over an entire antibiotic course. Int J Antimicrob Agents. 2014;43:470-3.

38. Burkhardt O. Ertapenem in critically ill patients with early-onset ventilatorassociated pneumonia: pharmacokinetics with special consideration of freedrug concentration. J Antimicrob Chemother. 2007;59:277-84.

39. Ulldemolins M, Kumar V, Majcher-Peszynska J, Drewelow B, Derendorf $H$, Welte T. Flucloxacillin dosing in critically ill patients with hypoalbuminemia: special emphasis on unbound pharmacokinetics. J Antimicrob Chemother. 2010;65:1771-8

40. Taccone FS, Laterre PF, Dugernier T, Spapen H, Delattre I, Wittebole X, De Backer D, Layeux B, Wallemacq P, Vincent IL, Jacobs F. Insufficient B-lactam concentrations in the early phase of severe sepsis and septic shock. Crit Care. 2010;14:R126.

41. Hanes SD, Wood C, Herring V, Croce MA, Fabian TC, Pritchard E, Boucher BA. Intermittent and continuous ceftazidime infusion for critically ill trauma patients. Am J Surg. 2000;179:436-40.

42. Garot D, Respaud R, Lanotte P, Simon N, Mercier E, Ehrmann S, Perrotin D, Dequin PF, Le Guellec C. Population pharmacokinetics of ceftriaxone in critically ill septic patients: a reappraisal. British J Clin Pharm. 2011;72:758-67.

43. Conil JM, Georges B, Mimoz O, Dieye E, Ruiz S, Cougot P, Samii K, Houin G, Saivin $S$. Influence of renal function on trough serum concentrations of piperacillin in intensive care unit patients. Intensive Care Med. 2006;32: 2063-6.

44. Kees MG, Minichmayr I, Moritz S, Beck S, Wicha SG, Kees F, Kloft C, Steinke T. Population pharmacokinetics of meropenem during continuous infusion in surgical ICU patients. J Clin Pharmacol. 2016;56:307-15.

45. Ramon-Lopez A, Allen JM, Thompson AH, Dheansa BS, James SE, Hanlan GW, Davies JG. Dosing regimen of meropenem for adults with severe burns: a population pharmacokinetic study with Monte Carlo simulations. J Antimicrob Chemother. 2015:70:882-90.

46. Blot S, Lipman J, Roberts DM, Roberts JA. The influence of acute kidney injury on antimicrobial dosing in critically ill patients: are dose reductions always necessary? Diagn Microbiol Infect Dis. 2014;79:77-84.

47. Roberts JA, Pea F, Lipman J. Clin Pharmacokinet. 2013:52:1-8.

48. Udy AA. Are standard doses of piperacillin sufficient for critically ill patients with augmented creatinine clearance? Crit Care. 2015:19-28.

49. Udy AA, Lipman J, Jarret P, Klein K, Wallis SC, Patel K, Kirkpatrick CMJ, Kruger PS, Paterson DL, Roberts MS, Roberts JA. Augmented renal clearance in the intensive care unit: an illustrative case series. Int J Antimicrob Agents. 2010; 35:606-8

50. Huttner A, Von Dach E, Renzoni A, Huttner B, Affaticati M, Pagani L, Daali Y, Pugin J, Karmime A, Fathi M, Lew D, Harbarth S. Augmented renal clearance, low Beta-lactam concentrations and clinical outcomes in the critically ill: An observational prospective cohort study. Int J Antimicrob Agents. 2015:45:385-39.

51. Carlier M, Carrette S, Roberts JA, Stove V, Verstraete A, Hoste E, Depuydt P, Decruyenaere J, Lipman J, Wallis SC, De Waele JJ. Meropenem and piperacillin/tazobactam prescribing in critically ill patients: does augmented 
renal clearance affect pharmacokinetic/pharmacodynamic target attainment when extended infusions are used? Crit Care. 2013;17:R84.

52. Kikuchi E, Kikuchi J, Nasuhara Y, Oizumi S, Ishizaka A, Nishimura M. Comparison of the pharmacodynamics of biapenem in bronchial epithelial lining fluid in healthy volunteers given half-hour and three-hour intravenous infusions. Antimicrob Agents Chemother. 2009:53:2799-803.

53. Mimoz O, Soreda S, Padoin C, Tod M, Petitjean O, Benhamou D. Ceftriaxone pharmacokinetics during iatrogenic hydroxyethyl starch-induced hypoalbuminemia. Anesthesiology. 2000;93:735-43.

54. Udy AA, Varghese JM, Altukroni M, Briscoe S, McWhinney BC, Ungerer JP, Lipman J, Roberts JA. Subtherapeutic initial b-lactam concentrations in select critically ill patients. Association between augmented renal clearance and low trough drug concentrations. Chest. 2012;142:30-9.

55. Wong G, Briscoe S, Adnan S, McWhinney B, Ungerer J, Lipman J, Roberts JA. Protein binding of beta-lactam antibiotics in critically ill patients: can we successfully predict unbound concentrations? Antimicrob Agents Chemother. 2013;57:6165-70

56. Schleibinger M, Steinbach C, Topper C, Kratzer A, Liebchen U, Kees F, Salzberger B, Kees MG. Protein binding characteristics and pharmacokinetics of ceftriaxone in intensive care unit patients. Br J Clin Pharmacol. 2015;80:525-33.

57. Matuszkiewicz-Rowińska J. Dosing of antibiotics in critically ill patients: are we left to wander in the dark? Polskie Archiwum Medycyny Wewnetrzney. 2012;122:630-40.

58. Fissell WH. Antimicrobial dosing in acute renal replacement. Adv Chronic Kidn Dis. 2013; https://doi.org/10.1053/j.ackd.2012.10.004.

59. Eyler RF, Mueller BA. Antimicrobial dosing in critically ill patients with acute kidney injury. Nat Rev Nephrol. 2011;7:226-35.

60. Lewis SJ, Mueller BA. Antibiotic dosing in critically ill patients receiving CRRT: underdosing is overprevalent. Semin Dial. 2014;27:441-5.

61. Harris LE, Reavesa AB, Kraussa AG, Grinerb J, Hudson JQ. Evaluation of antibiotic prescribing patterns in patients receiving sustained low-efficiency dialysis: opportunities for pharmacists. Int J Pharm Pract. 2013;21:55-61.

62. Morabito S, Guzzo I, Vitaliano E, Muzi L, Solazzo A, Pistolesi V, Pierucci A. Farmacocinetica degli Antibiotici nelle Terapie Sostitutive Renali Continue (CRRT). Gionale Italiano di Nefrologia. 2012;29:425-44.

63. Morabito S, Guzzo I, Vitaliano E, Muzi L, Solazzo A, Pistolesi V, Pierucci A. Principi di farmacocinetica e aggiustamento posologico dei farmaci nelle terapie sostitutive renali continue (CRRT). Giornale Italiano di Nefrologia. 2006:36:S127-38

64. Choi G, Gomersall CD, Tian Q, Joynt GM, Freebairn R, Lipman J. Principles of antibacterial dosing in continuous renal replacement therapy. Crit Care Med. 2009;37:2268-82.

65. Hites M, Dell'Anna AM, Scolletta S, Taccone FS. The challenges of multiple organ dysfunction syndrome and extra-corporeal circuits for drug delivery in critically ill patients. Adv Drug Deliv Rev. 2014;77:12-21.

66. Jamal J-A, Udy AA, Lipman J, Roberts JA. The impact of variation in renal replacement therapy settings on piperacillin, meropenem, and vancomycin drug clearance in the critically ill: an analysis of published literature and dosing regimens. Crit Care Med. 2014:42:1640-50.

67. Fish DN, Teitelbaum I, Abraham E. Pharmacokinetics and pharmacodynamics of imipenem during continuous renal replacement therapy in critically ill patients. Antimicrob Agents Chemother. 2005;49: 2421-8.

68. Malone RS, Fish DN, Abraham E, Teitelbaum I. Pharmacokinetics of cefepime during continuous renal replacement therapy in critically ill patients. Antimicrob Agents Chemother. 2001;45:3148-55.

69. Mueller SC, Majcher-Peszynska J, Hickstein H, Francke A, Pertschy A, Schulz A, Mundkowski R, Drewelow B. Pharmacokinetics of piperacillin-tazobactam in anuric intensive care patients during continuous venovenous hemodialysis. Antimicrob Agents Chemother. 2002;46:1557-60.

70. Roberts DM, Roberts JA, Roberts MS, Liu X, Nair P, Cole L, Lipman J, Bellomo $R$, on behalf of the RENAL Replacement Therapy Study Investigators. Variability of antibiotic concentrations in critically ill patients receiving continuous renal replacement therapy: A multicentre pharmacokinetic study. Crit Care Med. 2012;40:1523-8.

71. Banyai M, Thalhammer F, El Menyawi I, Heinz G, Traunmüller F, Siostrzonek P. Pharmacokinetics of cefpirome during continuous venovenous hemofiltration: Rationale for an 8-hour dosing interval. Clin Pharmacol Therapeut. 2000;67:368-72.

72. Eyler RF, Vilay AM, Nader AM, Heung M, Pleva M, Sowinski KM, DePestel DD, Sörgel F, Kinzig M, Mueller BA. Pharmacokinetics of ertapenem in critically ill patients receiving continuous venovenous hemodialysis or hemodiafiltration. Antimicrob Agents Chemother. 2014;58:1320-6.

73. Vossen MG, Wenisch JM, Maier-Salamon A, Fritsch A, Saria K, Zuba C, Jilch S, Lemmerer $\mathrm{R}$, Unger $\mathrm{M}$, Jaehde $U$, Jäger $\mathrm{W}$, Thalhammer F. Doripenem treatment during continuous renal replacement therapy. Antimicrob Agents Chemother. 2016:60:1687-94.

74. Carlier M, Taccone FS, Beumier M, Seylerd L, Cottone F, Jacobs F, Roberts JA. Population pharmacokinetics and dosing simulations of cefepime in septic shock patients receiving continuous renal replacement therapy. Int J Antimicrob Agents. 2015;46:413-9.

75. Seyler L, Cotton F, Taccone FS, De Backer D, Macours P, Vincent J-L, Jacobs F. Recommended b-lactam regimens are inadequate in septic patients treated with continuous renal replacement therapy. Crit Care. 2011;15:R137.

76. Roberts DM, Liu X, Roberts JA, Nair P, Cole L, Roberts MS, Lipman L, Bellomo R, on behalf of the RENAL Replacement Therapy Study Investigators. A multicenter study on the effect of continuous hemodiafiltration intensity on antibiotic pharmacokinetics. Crit Care. 2015; 19:84.

77. Ohchi T, Hidaka S, Goto K, Shitomi R, Nishida T, Abe T, Yamamoto S, Yasuda N, Hagiwara S, Noguchi T. Effect of hemopurification rate on doripenem pharmacokinetics in critically ill patients receiving high-flow continuous hemodiafiltration. Yakugaku Zasshi. 2011;131:1395-9.

78. Arzuaga A, Maynar J, Gascón AR, Isla A, Corral E, Fonseca F, SánchezIzquierdo JA, Rello J, Canut A, Pedraz JL. Influence of renal function on the pharmacokinetics of piperacillin/tazobactam in intensive care unit patients during continuous venovenous hemofiltration. J Clin Pharmacol. 2005;45: 168-76.

79. Isla A, Maynar J, Sánchez-Izquierdo JA, Gascón AR, Arzuaga A, Corral E, Pedraz JL. Meropenem and continuous renal replacement therapy: in vitro permeability of 2 continuous renal replacement therapy membranes and influence of patient renal function on the pharmacokinetics in critically ill patients. J Clin Pharmacol. 2005;45:1294-304.

80. Ulldemolins A, Soy D, Llaurado-Serra M, Vaquer S, Castro P, Rodríguez AH, Pontes C,J, Calvo G, Torres A, Martín-Loeches I. Meropenem population pharmacokinetics in critically ill patients with septic shock and continuous renal replacement therapy: influence of residual diuresis on dose requirements. Antimicrob Agents Chemother. 2015;59:5520-8.

81. Bouman CSC, van Kan HJM, Koopmans RP, Korevaar JC, Schultz MJ, Vroom MB. Discrepancies between observed and predicted continuous venovenous hemofiltration removal of antimicrobial agents in critically ill patients and the effects on dosing. Intensive Care Med. 2006;32:2013-9.

82. Kielstein JT, Czock D, Schöpke T, Hafer C, Bode-Böger SM, Kuse E, Keller F, Fliser D. Pharmacokinetics and total elimination of meropenem and vancomycin in intensive care unit patients undergoing extended daily dialysis. Crit Care Med. 2006;34:51-6.

83. Lorenzen JM, Broll M, Kaever V, Burhenne H, Hafer C, Clajus C, Knitsch W, Burkhardt O, Kielstein JT. Pharmacokinetics of ampicillin/sulbactam in critically ill patients with acute kidney injury undergoing extended dialysis. Clin J Am Soc Nephrol. 2012;7:385-90.

84. Burkhardt $\mathrm{O}$, Hafer $\mathrm{C}$, Langhoff A, Kaever V, Kumar V, Welte T, Haller H, Fliser D, Kielstein JT. Pharmacokinetics of ertapenem in critically ill patients with acute renal failure undergoing extended daily dialysis. Nephrol Dial Transplant. 2009;24:267-71.

85. Tamme K, Oselin K, Kipper K, Tasa T, Metsvaht T, Karjagin J, Herodes K, Kern $\mathrm{H}$, Starkopf J. Pharmacokinetics and pharmacodynamics of piperacillin/ tazobactam during high volume haemodiafiltration in patients with septic shock. Acta Anaesthesiol Scand. 2016;60:230-40.

86. Bourquin V, Ponte B, Saudan P, Martin P-Y. Adaptation posologique des médicaments couramment utilise's en réanimation lors d'épuration extrarénale continue. Néphrol Thérapeut. 2009:5:533-41.

87. Trotman RL, Williamson JC, Shoemaker DM, Salzer WL. Antibiotic dosing in critically ill adult patients receiving continuous renal replacement therapy. Clin Infect Dis. 2005:41:1159-66.

88. Brett H, Matzke GR, Dager WE. Antimicrobial dosing concepts and recommendations for critically ill adult patients receiving continuous renal replacement therapy or intermittent hemodialysis. Pharmacotherapy. 2009; 29:562-77.

89. De Waele JJ, Carlier M. Beta-lactam antibiotic dosing during continuous renal replacement therapy: how can we optimize therapy? Crit Care. 2014; 18:158. 
90. Kielstein JT, Burkhardt O. Dosing of antibiotics in critically ill patients undergoing renal replacement therapy. Curr Pharm Biotechnol. 2011;12:2015-9.

91. Churchwell MD, Mueller BA. Drug dosing during continuous renal replacement therapy. Semin Dial. 2009;22:185-8.

92. Vossen MF, Thalhammer F. Effects of renal replacement therapy on antimicrobial therapy. Curr Clin Pharmacol. 2013;8:39-45.

93. Goldstein SL, Nolin TD. Lack of drug dosing guidelines for critically ill patients receiving continuous renal replacement therapy. Clin Pharmacol Therapeut. 2014;96:159-61.

94. Scoville BA, Mueller BA. Medication dosing in critically ill patients with acute kidney injury treated with renal replacement therapy. Am J Kidney Dis. 2013;61:490-500

95. Mueller BA, Pasko DA, Sowinski KM. Higher renal replacement therapy dose delivery influences on drug therapy. Artif Organs. 2003;27:808-14.

96. Ulldemolins M, Vaquer S, Llauradó-Serra M, Pontes C, Calvo G, Soy D, Martín-Loeches I. Beta-lactam dosing in critically ill patients with septic shock and continuous renal replacement therapy. Crit Care. 2014;18:227.

97. Shekar, Fraser JF, Smith MT, Roberts JA. Pharmacokinetic changes in patients receiving extracorporeal membrane oxygenation. doi: https://doi. org/10.1016/j.jcrc.2012.02.013.

98. Shekar K, Roberts JA, Mcdonald Cl, Fisquet S, Barnett AG, Mullany DV, Ghassabian S, Wallis SC, Fung YL, Smith MT, Fraser JF. Sequestration of drugs in the circuit may lead to therapeutic failure during extracorporeal membrane oxygenation. Crit Care. 2012;16:R194.

99. Dzierba AL, Abrams D, Brodie D. Medicating patients during extracorporeal membrane oxygenation: the evidence is building. Crit Care. 2017;21:66.

100. Donadello K, Antonucci E, Cristallini S, Roberts JA, Beumier M, Scolletta S, Jacobs F, Rondelet B, de Backer D, Vincent J-L, Taccone FS. $\beta$-Lactam pharmacokinetics during extracorporeal membrane oxygenation therapy: A case-control study. Int J Antimicrob Agents. 2015; 45: 278-282.

101. Shekar K, Fraser JF, Taccone FS, Welch S, Wallis SC, Mullany DV, Lipman J, Roberts JA, and on behalf of the ASAP ECMO Study Investigators. The combined effects of extracorporeal membrane oxygenation and renal replacement therapy on meropenem pharmacokinetics: a matched cohort study. Crit Care. 2014;18:565.

102. Welsch C, Augustin P, Allyn J, Massias L, Montravers P, Allou N. Alveolar and serum concentrations of imipenem in two lung transplant recipients supported with extracorporeal membrane oxygenation. Transpl Infect Dis. 2015;17:103-5.

103. Perrott J, Mabasa VH, Ensom MHH. Comparing outcomes of meropenem administration strategies based on pharmacokinetic and pharmacodynamic principles: a qualitative systematic review. Ann Pharmacother. 2010:44:557-64.

104. Mah GT, Mabasa VH, Chow I, Ensom MHH. Evaluating outcomes associated with alternative dosing strategies for piperacillin/tazobactam: a qualitative systematic review. Ann Pharmacother. 2012;46:265-75.

105. Burgess SV, Mabasa VH, Chow I, Ensom MHH. Evaluating outcomes of alternative dosing strategies for cefepime: a qualitative systematic review. Ann Pharmacother. 2015; https://doi.org/10.1177/1060028014564179.

106. Bauer KA, West JE, O'Brien JM, Goff DA. Extended-infusion cefepime reduces mortality in patients with Pseudomonas aeruginosa Infections. Antimicrob Agents Chemother. 2013;57:2907-12.

107. Roberts JA, Boots R, Rickard CM, Thomas P, Quinn J, Roberts DM, Richards B, Lipman J. Is continuous infusion ceftriaxone better than once-a-day dosing in intensive care? A randomized controlled pilot study. J Antimicrob Chemother. 2007:59:285-91.

108. Lorente L, Lorenzo L, Martín MM, Jiménez A, Mora ML. Meropenem by continuous versus intermittent infusion in ventilator-associated pneumonia due to Gram-negative bacilli. Ann Pharmacother. 2006;40:219-23.

109. Roberts JA, Kirkpatrick CMJ, Roberts MS, Robertson TA, Dalley AJ, Lipman J. Meropenem dosing in critically ill patients with sepsis and without renal dysfunction: intermittent bolus versus continuous administration? Monte Carlo dosing simulations and subcutaneous tissue distribution. J Antimicrob Chemother. 2009;64:142-50.

110. Rafati MR, Rouini MR, Mojtahedzadeh M, Najafi A, Tavakoli H, Gholami K Fazeli MR. Clinical efficacy of continuous infusion of piperacillin compared with intermittent dosing in septic critically ill patients. Int J Antimicrob Agents. 2006;28:122-7.

111. Duszynskaa W, Taccone FS, Switala M, Hurkacz M, Kowalska-Krochmal B, Kübler A. Continuous infusion of piperacillin/tazobactam in ventilatorassociated pneumonia: a pilot study on efficacy and costs. Int J Antimicrob Agents. 2012;39:153-8.
112. Roberts JA, Kirkpatrick CMJ, Roberts MS, Dalley AJ, Lipman J. First-dose and steady-state population pharmacokinetics and pharmacodynamics of piperacillin by continuous or intermittent dosing in critically ill patients with sepsis. J Antimicrob Agents. 2010;35:156-63.

113. Chytra I, Stepan M, Benes J, Pelnar P, Zidkova A, Bergerova T, Pradl R, Kasal E. Clinical and microbiological efficacy of continuous versus intermittent application of meropenem in critically ill patients: a randomized open-label controlled trial. Crit Care. 2012;16:R113.

114. Falagas ME, Tansarli GS, Ikawa K, Vardakas KZ. Clinical outcomes with extended or continuous versus short-term intravenous infusion of carbapenems and piperacillin/tazobactam: a systematic review and metaanalysis. Clin Infect Dis. 2013;56:272-82.

115. Lorente L, Jimenez A, Palmero S, Jimenez JJ, Iribarren JL, Santana M, Martin MM, Mora ML. Comparison of clinical cure rates in adults with ventilatorassociated pneumonia treated with intravenous ceftazidime administered by continuous or intermittent infusion: a retrospective, nonrandomized, open-label, historical chart review. Clin Ther. 2007;29:2433-9.

116. Dulhunty JM, Roberts JA, Davis JS, Webb SAR, Bellomo R, Gomersall C, Shirwadkar C, Eastwood GM, Myburgh J, Paterson DL, Lipman J. Continuous infusion of beta-lactam antibiotics in severe sepsis: a multicenter doubleblind, Randomized Controlled Trial. Clin Infect Dis. 2013;56:236-44.

117. Gonçalves-Pereira J, Oliveira BS, Janeiro S, Estilita J, Monteiro C, Salgueiro A, Vieira A, Gouveia J, Paulino C, Bento L, Póvoa P. Continuous infusion of piperacillin/ tazobactam in septic critically ill patients - a multicenter propensity matched analysis. PLoS One. 2012;7:e4984. https://doi.org/10.1371/journal.pone.0049845.

118. Abdul-Aziz MH, Staatz CE, Kirkpatrick CMJ, Lipman J, Roberts JA. Continuous infusion vs. bolus dosing: implications for beta-lactam antibiotics. Minerva Anestesiol. 2012;78:94-10.

119. Nicolau DP, McNabb J, Lacy MK, Quintiliani R, Nightingale $\mathrm{CH}$. Continuous versus intermittent administration of ceftazidime in intensive care unit patients with nosocomial pneumonia. Int J Antimicrob Agents. 2001;17: 497-504.

120. Huang $H$, Hang S, Zhu P, Xi X. Continuous versus intermittent infusion of cefepime in neurosurgical patients with post-operative intracranial infections. Int J Antimicrob Agents. 2014;43:68-72.

121. van Zanten ARH, Oudijk M, Nohlmans-Paulssen MKE, van der Meer YG, Girbes ARJ, Polderman KH. Continuous vs. intermittent cefotaxime administration in patients with chronic obstructive pulmonary disease and respiratory tract infections: pharmacokinetics/pharmacodynamics, bacterial susceptibility and clinical efficacy. Br J Clin Pharmacol. 2006;63:100-9.

122. Lee GC, Liou H, Yee R, Quan CF, Neldner K. Outcomes of extended-infusion piperacillin-tazobactam: a retrospective analysis of critically ill patients. Clin Ther. 2012;34:2297-300.

123. Jaruratanasirikul S, Limapichat T, Jullangkoon M, Aeinlang N, Ingviya N, Wongpoowarak W. Pharmacodynamics of meropenem in critically ill patients with febrile neutropenia and bacteraemia. Int J Antimicrob Agents. 2011:38:231-6.

124. Angus BJ, Smith MD, Suputtamongkol Y, Mattie H, Walsh AL, Wuthiekanun V, Chaowagul W, White NJ. Pharmacokinetic-pharmacodynamic evaluation of ceftazidime continuous infusion vs intermittent bolus injection in septicaemic melioidosis. Br J Clin Pharmacol. 2000:49:184-91.

125. Roos JF, Bulitta J, Lipman J, Kirkpatrick CMJ. Pharmacokineticpharmacodynamic rationale for cefepime dosing regimens in intensive care units. J Antimicrob Chemother. 2006;58:987-93.

126. Breilh D, Fleureau C, Gordien J-B, Joanes-Boyau O, Texier-Maugein J, Rapaport S, Boselli E, Janvier G, Saux M-C. Pharmacokinetics of free ertapenem in critically ill septic patients: intermittent versus continuous infusion. Minerva Anestesiol. 2011;77:1058-62.

127. Roberts JA, Roberts MS, Robertson TA, Daley AJ, Lipman J. Piperacillin penetration into tissue of critically ill patients with sepsis-Bolus versus continuous administration? Crit Care Med. 2009;37:926-33.

128. Lodise TP, Lomaestro B, Drusano GL. Piperacillin-tazobactam for Pseudomonas aeruginosa infection: clinical implications of an extendedinfusion dosing strategy. Clin Infect Dis. 2007;44:357-63.

129. Sakka SG, Glauner AK, Bulitta JB, Kinzig-Schippers M, Pfister W, Drusano GL, Sorgel F. Population pharmacokinetics and pharmacodynamics of continuous versus short-term infusion of imipenem-cilastatin in critically ill patients in a randomized, controlled trial. Antimicrob Agents Chemother. 2007;51:3304-10.

130. Nicasio AM, Ariano RE, Zelenitski SA, Kim A, Crandon JL, Kuti JL, Nicolau DP. Population pharmacokinetics of high-dose, prolonged-infusion cefepime in 
adult critically ill patients with ventilator-associated pneumonia. Antimicrob Agents Chemother. 2009;53:1476-81.

131. Arnold HM, Hollands JM, Skrupky LP, Smith JR, Juang PH, Hampton NB, McCormick S, Reichley RM, Hoban A, Hoffman J, Micek ST, Kollef MH. Prolonged infusion antibiotics for suspected Gram-negative infections in the ICU: a before-after study. Ann Pharmacother. 2013;47:170-80.

132. Yusuf E, Spapen H, Piérard D. Prolonged vs. intermittent infusion of piperacillin/tazobactam in critically ill patients: A narrative and systematic review. J Crit Care. 2014;29:1089-95.

133. Cheatham SC, Fleming MR, Healy DP, Kyoung E, Shea KM, Humphrey ML, Kays MB. Steady-state pharmacokinetics and pharmacodynamics of meropenem in morbidly obese patients hospitalized in an intensive care unit. J Clin Pharmacol. 2013;54:324-30.

134. Laterre P-F, Wittebole X, Van de Velde S, Muller AE, Mouton JW, Carryn S, Tulkens PM, Dugernir T. Temocillin ( $6 \mathrm{~g}$ daily) in critically ill patients: continuous infusion versus three times daily administration. J Antimicrob Chemother. 2015;70:891-8.

135. Langgartner J, Lehn N, Gluck T, Herzig H, Kees F. Comparison of the pharmacokinetics of piperacillin and sulbactam during intermittent and continuous intravenous infusion. Chemotherapy. 2007;53:370-7.

136. Langgartner J, VasoldA, Glück T, Reng M, Kees F. Pharmacokinetics of meropenem during intermittent and continuous intravenous application in patients treated by continuous renal replacement therapy. Int Care Med. 2008; 34:1091-96.

137. Langgartner J, Vasold A, Glück T, Reng M, Kees F. Pharmacokinetics of meropenem during intermittent and continuous intravenous application in patients treated by continuous renal replacement therapy. Intens Care Med. 2008:34:1091-6.

138. Jamal J-A, Mat-Nor MB, Mohamad-Nor F-S, Udy AA, Wallis SC, Lipman J, Roberts JA. Pharmacokinetics of meropenem in critically ill patients receiving continuous venovenous haemofiltration: A randomised controlled trial of continuous infusion versus intermittent bolus administration. Int J Antimicrob Agents. 2015;45:41-5.

139. Asín-Prieto E, Rodriguez-Gasco A, Tracóniz I, Soraluce A, Maynar J, SánchezIzquierdo JA, Isla A. Population pharmacokinetics of piperacillin and tazobactam in critically ill patients undergoing continuous renal replacement therapy: application to pharmacokinetic/pharmacodynamic analysis. J Antimicrob Chemother. 2014;69:180-9.

140. Obrink-Hansen K, Juul RV, Storgaard M, Thomsen MK, Hardlei TF, Brock B, Kreilgaard M, Gjedsted J. Population pharmacokinetics of piperacillin in the early phase of septic shock: does standard dosing result in therapeutic plasma concentrations? Antimicrob Agents Chemother. 2015;59:7018-26.

141. D'Agostino C, Rhodes NJ, Skoglund E, Roberts JA. Microbiologic clearance following transition from standard infusion piperacillin-tazobactam to extended-infusion for persistent Gram- negative bacteremia and possible endocarditis: A case report and review of the literature. J Infect Chemother. 2015;21:742-6

142. Lips M, Siller M, Strojil J, Urbánek K, Balík M, Suchánková H. Pharmacokinetics of imipenem in critically ill patients during empirical treatment of nosocomial pneumonia: A comparison of $0.5-\mathrm{h}$ and $3-\mathrm{h}$ infusions. Int J Antimicrob Agents. 2014:44:358-62

143. De Waele J, Carlier M, Hoste E, Depuydt P, Decruyenaere J, Wallis SC, Lipman J, Roberts JA. Extended versus bolus infusion of meropenem and piperacillin: a pharmacokinetic analysis. Minerva Anestesiol. 2014;80:1302-9.

144. Dulhunty JM, Roberts JA, Davis JS, SAR W, Bellomo R, Gomersall C, Shirwadkar C, Eastwood GM, Myburgh J, Paterson DL, Starr T, Paul SK, Lipman J, for the BLING II Investigators for the ANZICS Clinical Trials Group. A multicenter randomized trial of continuous versus intermittent b-lactam infusion in severe sepsis. Am J Respir Crit Med. 2015;192:1298-305.

145. Abdul-Aziz MH, Lipman J, Akova M, Bassetti M, De Waele JJ, Dimopoulos G, Dulhunty J, Kaukonen K-M, Koulenti D, Martin C, Montravers P, Rello J, Rhodes A, Starr T, Wallis SC, Roberts JA, on behalf of the DALI Study Group. Is prolonged infusion of piperacillin/tazobactam and meropenem in critically ill patients associated with improved pharmacokinetic/ pharmacodynamic and patient outcomes? An observation from the Defining Antibiotic Levels in Intensive care unit patients (DALI) cohort. J Antimicrob Chemother. 2016;71:196-207.

146. Boyadjiev I, Boulamery A, Simon N, Martin C, Bruquerolle B, Leone M. Penetration of ertapenem into muscle measured by in vivo microdialysis in mechanically ventilated patients. Antimicrob Agents Chemother. 2011;55: 3573-5.
147. Karjagin J, Lefeuvre S, Oselins K, Kipper K, Marchand S, Tikkerberi A, Starkopf J, Coue W, Sawchuk RJ. Pharmacokinetics of meropenem determined by microdialysis in the peritoneal fluid of patients with severe peritonitis associated with septic shock. Clin Pharmacol Ther. 2008;83:452-9.

148. Zeitlinger MA, Erovic BM, Sauermann R, Georgopoulos A, Muller M, Joukhadar C. Plasma concentrations might lead to overestimation of target site activity of piperacillin in patients with sepsis. J Antimicrob Chemother. 2005;56:703-8.

149. Goldwater PN. Cefotaxime and ceftriaxone cerebrospinal fluid levels during treatment of bacterial meningitis in children. Int J Antimicrob Agents. 2005; 26:408-11.

150. Do L, Udy AA, Roberts JA, Lipman J. Antibacterial therapeutic drug monitoring in cerebrospinal fluid: difficulty in achieving adequate drug concentrations. J Neurosurg. 2013;118:297-301.

151. Abdul-Aziz MH, McDonald C, McWhinney B, Ungerer JPJ, Lipman J, Roberts JA. Low flucloxacillin concentrations in a patient with central nervous system infection: the need for plasma and cerebrospinal fluid drug monitoring in the ICU. Ann Pharmacother. 2014;48:1380-4.

152. Cies JJ, Moore WS, Calaman S, Brown M, Narayan P, Parker J, Chopra A. Pharmacokinetics of continuous-infusion meropenem for the treatment of Serratia marcescens ventriculitis in a pediatric patient. Pharmacotherapy. 2015;35:e32-6.

153. Dahyot-Fizelier C, Frasca D, Grégoire N, Adier C, Mimoz O, Debaene B, Couet W, Marchand S. Microdialysis study of cefotaxime cerebral distribution in patients with acute brain injury. Antimicrob Agents Chemother. 2013;6:2738-42.

154. Morita A, Kamei S, Minami M, Yoshida K, Kawabata S, Kuroda H, Suzuki Y, Araki N, Iwasaki Y, Kobayashi R, Hayashi N, Hirayama T, Ochiai J, Ueda M, Yamagishi Y, Niwa J, Shindo K, Fukushima Y, Takita T, Sato T, Sato S, Mikamo $H$, Iwata S. Open-label study to evaluate the pharmacodynamics, clinical efficacy, and safety of meropenem for adult bacterial meningitis in Japan. J Infect Chemother. 2014;20:535-40.

155. Tsumura R, Ikawa K, Morikawa N, Ikeda K, Shibukawa M, lida K, Kurisu K. The pharmacokinetics and pharmacodynamics of meropenem in the cerebrospinal fluid of neurosurgical patients. J Chemother. 2008;20:615-21.

156. Nicasio AM, Quintiliani R Jr, DeRyke CA, Kuti JL, Nicolau DP. Treatment of Serratia marcescens meningitis with prolonged infusion of meropenem. Ann Pharmacother. 2007;41:1077-81.

157. Frasca D, Dahyot-Fizelier C, Couet W, Debaene B, Mimoz O, Marchand S. Brain microdialysis distribution study of cefotaxime in a patient with traumatic brain injury. Br J Anesthesiol. 2012;109:830-1.

158. Wang Q, Wu Y, Chen B, Zhou J. Drug concentrations in the serum and cerebrospinal fluid of patients treated with cefoperazone/sulbactam after craniotomy. BMC Anesthesiol. 2015;15:33.

159. Rodvold KA, Nicolau DP, Lodise TP, Khashab M, Noel GJ, Kahn JB, Gotfried M, Murray SA, Nicholson S, Laohavaleeson S, Tessier PR, Drusano GL. Identifying exposure targets for treatment of staphylococcal pneumonia with ceftobiprole. Antimicrob Agents Chemother. 2009;53:3294-301.

160. Bayat S, Louchahi K, Verdière B, Anglade D, Rahoui A, Sorin P-M, Tod M, Petitjean O, Fraisse F, Grimbert FA. Comparison of 99mTc-DTPA and urea for measuring cefepime concentrations in epithelial lining fluid. Eur Respir J. 2004;24:150-6.

161. Boselli E, Breilh B, Rimmelé T, Guillaume C, Xuereb F, Saux M-C, Bouvet L, Chassard D, Allaouchiche B. Alveolar concentrations of piperacillin/ tazobactam administered in continuous infusion to patients with ventilatorassociated pneumonia. Crit Care Med. 2008;36:1500-6.

162. Cousson J, Floch T, Guillard T, Vernet V, Raclot P, Wolak-Thierry A, Jolly D. Lung concentrations of ceftazidime administered by continuous versus intermittent infusion in patients with ventilator-associated pneumonia. Antimicrob Agents Chemother. 2015;59:1905-9.

163. Burkhardt O, Majcher-Peszynska J, Borner K, Mundkowski R, Drewelow B, Derendorf $\mathrm{H}$, Welte T. Penetration of ertapenem into different pulmonary compartments of patients undergoing lung surgery. J Clin Pharmacol. 2005; 45:659-65.

164. Boselli E, Breilh D, Saux M-C, Gordien J-B, Allaouchiche B. Pharmacokinetics and lung concentrations of ertapenem in patients with ventilator-associated pneumonia. Intensive Care Med. 2006;32:2059-62.

165. Boselli E, Breilh D, Rimmel T, Poupelin J-C, Saux M-C, Chassard D, Allaouchiche A. Plasma and lung concentrations of ceftazidime administered in continuous infusion to critically ill patients with severe nosocomial pneumonia. Intensive Care Med. 2004;30:989-91. 
166. Felton TW, McCalman K, Malagon I, Isalska B, Whalley S, Goodwin J, Bentley AM, Hope WW. Pulmonary penetration of piperacillin and tazobactam in critically ill patients. Clin Pharmacol Ther. 2014;96:438-48.

167. Boselli, et al. Steady-state plasma and intrapulmonary concentrations of cefepime administered in continuous infusion in critically ill patients with severe nosocomial pneumonia. Crit Care Med. 2003;31(8):2102-6.

168. Boselli E, Breilh D, Cannesson M, Xuereb F, Rimmel T, Chassard D, Saux M-C, Allaouchiche B. Steady-state plasma and intrapulmonary concentrations of piperacillin/tazobactam $4 \mathrm{~g} / 0.5 \mathrm{~g}$ administered to critically ill patients with severe nosocomial pneumonia. Intens Care Med. 2004;30:976-9.

169. Lodise TP, Kinzig-Schippers M, Drusano GL, Loos U, Vogel F, Bulitta J, Hinder M, Sorgel F. Use of population pharmacokinetic modeling and Monte Carlo simulation to describe the pharmacodynamic profile of cefditoren in plasma and epithelial lining fluid. Antimicrob Agents Chemother. 2008;52:1945-51.

170. Xiao AJ, Caro L, Popejoy MW, Huntigton JA, Kullar R. PK/PD target attainment with ceftolozane/tazobactam using Monte Carlo simulation in patients with various degrees of renal function, including augmented renal clearance and end-stage renal disease. Infect Dis Ther. 2017;6:137-48.

171. Chandorkar G, Xiao AJ, Mouksassi M-S, Hershberger E, Krishna G. Population pharmacokinetics of ceftolozane/tazobactam in healthy volunteers, subjects with varying degrees of renal function and patients with bacterial infections. J Clin Pharmacol. 2015;55:230-9.

172. Van Duin B, Bonomo RA. Ceftazidime/avibactam and ceftolozane/ tazobactam: second-generation $\beta$-lactam/ $\beta$-lactamase inhibitor combinations. Clin Infect Dis. 2016;63:234-41.

173. Xiao AJ, Miller BW, Huntington JA, Nicolau DP. Ceftolozane/tazobactam pharmacokinetic/pharmacodynamic-derived dose justification for phase 3 studies in patients with nosocomial pneumonia. J Clin Pharmacol. 2016;56: 56-66.

174. Veillette JJ, Truong J, Forland SC. Pharmacokinetics of ceftazidimeAvibactam in two patients with KPC-Producing Klebsiella pneumoniae Bacteremia and renal Impairment. Pharmacotherapy. doi:org/https://doi.org/ 10.1002/phar.1840

175. Oliver WD, Heil EL, Gonzales JP, Mehrotra S, Robinett K, Saleeb P, Nicolau DP. Ceftolozane-tazobactam pharmacokinetics in a critically ill patient on continuous venovenous hemofiltration. Antimicrob Agents Chemother. 2016;60:1899-901.

176. Bremmer DN, Nicolau DP, Burcham P, Chunduri A, Shidham G, Bauer KA. Ceftolozane/tazobactam pharmacokinetics in a critically ill adult receiving continuous renal replacement therapy. Pharmacotherapy. Doi.org/https:// doi.org/10.1002/phar.1744.

177. Stokem K, Zuckerman JB, Nicolau DP, Wungwattana M, Sears EH. Use of ceftolozane-tazobactam in a cystic fibrosis patient with multidrugresistant pseudomonas infection and renal insufficiency. Respir Med Case Rep. 2018; 23:8-9.

178. Fugate JE, Kalimullah EA, Hocker SE, Clark SL, Wijdicks EFM, Rabinstein AA. Cefepime neurotoxicity in the intensive care unit: a cause of severe, underappreciated encephalopathy. Crit Care. 2013;17:R264.

179. Shaheen T, Volles D, Calland F, Sifri CD, Mytinger J, Hagspiel K, Sawyer R, Bonati H. Cefepime-associated status epilepticus in an ICU patient with renal failure. J Chemother. 2009;21:65-7.

180. Alvarez SD, Aragon MCFG, Moreno A, Alonso FP, Cook HJ, Cárdenas G, SotoHernández JL. Clinical and electroencephalographic assessment of cefepime during treatment of nosocomial infections in neurological patients. Cent Nerv Syst Agents Med Chem. 2011;11:1-5.

181. Finkelsztejn A, Cabral L, Bragatti JÁ, da Silva AV, Schuh AFS. Imipenemassociated encephalopathy. Arquivo Neuropsiquiatria. 2010;68:137-9.

182. Smith NL, Freebairn RC, Park MAJ, Wallis SC, Roberts JA, Lipman J. Therapeutic drug monitoring when using cefepime in continuous renal replacement therapy: seizures associated with cefepime. Crit Care Resusc. 2012;14:312-5.

183. Collins RD, Tverdek FP, Bruno JJ, Coyle EA. Probable nonconvulsive status epilepticus with the use of high-dose continuous infusion ceftazidime. J Pharm Pract. 2016;29:564-8.

184. Beumier M, Casu GS, Hites M, Wolff F, Cotton F, Vincent J-L, Jacobs F, Taccone FS. Elevated $\beta$-lactam concentrations associated with neurological deterioration in ICU septic patients. Minerva Anestesiol. 2015;81:497-506.

185. Fritz G, Barner C, Schindler R, Boemke W, Falke K. Amoxicillin-induced acute renal failure. Nephrol Dial Transp. 2003;18:1660-2.

186. Polderman KH, Girbes ARJ. Piperacillin-induced magnesium and potassium loss in intensive care unit patients. Intensive Care Med. 2002;28:520-2.
187. Lambden SP, Akeru J, Barrett NA. Acute intravascular hemolysis associated with intravenous administration of meropenem in a sixty-year-old man. Can J Clin Pharmacol. 2010;17:e64-6.

188. Marik PE, Parekh P. Life-threatening piperacillin-induced immune haemolysis in a patient with cystic fibrosis. BMJ Case Rep. 2013; https://doi.org/10.1136/ bcr-2012-007801.

189. Yang C-J, Hwang J-J, Hung J-Y, Chong I-W, Huang M-S. Extreme thrombocytosis under the treatment by amoxicillin/clavulanate. Pharm World Sci. 2006;28:326-8.

190. Lim PP, Chong CP, Abdul AN. Cefepime-associated thrombocytopenia in a critically ill patient. Int J Clin Pharmacol. 2011;33:902-4.

191. Macwilliam JL, Mistry R, Floyd MS Jr, Baird AD. Piperacillin/tazobactam induced thrombocytopaeniaa delayed response. BMJ Case Rep. 2012; https://doi.org/10.1136/bcr.03.2012.5981.

192. Rousan TA, Aldoss IT, Cowley BD Jr, Curtis BR, Bougie DW, Aster RH, George JN. Recurrent acute thrombocytopenia in the hospitalized patient: Sepsis, DIC, HIT, or antibiotic-induced thrombocytopenia. Am J Hematol. 2010;85:71-4.

193. Nguyen VD, Tourigny JF, Roy R, Brouillette D. Rapid-onset thrombocytopenia following piperacillin-tazobactam reexposure. Pharmacotherapy. 2015;35:e326-30.

194. Whitman CB, Joseph JM, Sjoholm LO. Cephalosporin-induced leukopenia following rechallenge with cefoxitin. Ann Pharmacother. 2008;42:1327-32.

195. Lambourne J, Kitchen J, Hughes C, Merry C. Piperacillin/tazobactam-induced paresthesiae. Ann Pharmacother. 2006;40:977-9.

196. Nag DS, Samaddar DP, Kant S, Mahanty PR. Perianesthetic refractory anaphylactic shock with cefuroxime in a patient with history of penicillin allergy on multiple antihypertensive medications. Rev Brasil Anestesiol. 2017; 67:217-20.

197. Lin Y-F, Yang C-H, Sindy H, Lin J-Y, Hui C-YR, Tsai Y-C, Wu TS, Huang CT, Kao K-C Hu H-C, Chiu C-H, Hung S-I, Chung W-H. Severe cutaneous adverse reactions related to systemic antibiotics. Clin Infect Dis. 2014;58:1377-85.

198. Hayashi, et al. Beta-Lactam therapeutic drug monitoring in the critically ill: optimising drug exposure in patients with fluctuating renal function and hypoalbuminaemia. Int J Antimicrob Agents. 2013;41:162-6.

199. Hites M, Taccone FS, Wolff F, Cotton F, Beumier M, De Backer D, Roisin S, Lorent S, Surin R, Seyler L, Vincent J-L, Jacobs F. Case-control study of drug monitoring of beta-lactams in obese critically ill patients. Antimicrob Agents Chemother. 2013;57:708-15.

200. Blondiaux N, Wallet F, Favory R, Onimus T, Nseir S, Courcol RJ, Durocher A, Roussel-Delvallez M. Daily serum piperacillin monitoring is advisable in critically ill patients. 2010; https://doi.org/10.1016/j.jantimicag.2010.01.018.

201. Pea F, Cojutti P, Sbrojavacca R, Cadeo B, Cristini F, Bulfoni A, Furlanut M. TDM-guided therapy with daptomycin and meropenem in a morbidly obese, Critically III Patient. Ann Pharmacother. 2011;45:e37.

202. Crandon JL, Ariano RE, Zelenitsky SA, Nicasio AM, Kuti JL, Nicolau DP. Optimization of meropenem dosage in the critically ill population based on renal function. Intensive Care Med. 2011;37:632-8.

203. Robatel C, Decosterd LA, Biollaz J, Eckert P, Schaller MD, Buclin T. Pharmacokinetics and dosage adaptation of meropenem during continuous venovenous hemodiafiltration in critically ill patients. J Clin Pharmacol. 2003; 43:1329-40.

204. Kawano S, Matsumoto K, Hara R, Kuroda Y, Ikawa K, Morikawa N, Horino T, Hori S, Kizu J. Pharmacokinetics and dosing estimation of meropenem in Japanese patients receiving continuous veno-venous hemodialysis. J Infect Chemother. 2015:21:476-8

205. Bugge JF. Pharmacokinetics and drug dosing adjustments during continuous venovenous hemofiltration or hemodiafiltration in critically ill patients. Acta Anaesthesiol Scand. 2001;45:929-34.

206. Casu GS, Hites M, Jacobs F, Cotton F, Wolff F, Beumier M, De Backer D, Vincent J-L, Taccone FS. Can changes in renal function predict variations in beta-lactam concentrations in septic patients? Int J Antimicrob Agents. 2013:42:422-8.

207. De Waele JJ, Carrette S, Carlier M, Stove V, Boelens J, Claeys G, Leroux-Roels I, Hoste E, Depuydt P, Decruyenaere J, Verstraete AG. Therapeutic drug monitoring-based dose optimisation of piperacillin and meropenem: a randomised controlled trial. Intensive Care Med. 2014:40:380-7.

208. Sime FB, Roberts MS, Tiong IS, Gardner JH, Lehman S, Peake SL, Hahn U, Warner MS, Roberts JA. Can therapeutic drug monitoring optimize exposure to piperacillin in febrile neutropenic patients with haematological malignancies? A randomized controlled trial. J Antimicrob Chemother. 2015; 70:2369-75. 
209. Neuner EA, Ahrens CL, Groszek JJ, Isada C, Vogelbaum MA, Fissell WH, Bhimraj A. Use of therapeutic drug monitoring to treat Elizabethkingia meningoseptica meningitis and bacteraemia in an adult. J Antimicrob Chemother. 2012; https://doi.org/10.1093/jac/dks053.

210. Roberts JA, Ulldemolins M, Roberts MS, McWhinney B, Ungerer J, Paterson DL, Lipman J. Therapeutic drug monitoring of Beta-lactams in critically ill patients: proof of concept. Int J Antimicrob Agents. https://doi.org/10.1016/ j.jiantimicag.2010.06.008.

211. Roberts JA, Norris R, Paterson DL, Martin JH. Therapeutic drug monitoring of antimicrobials. Br J Clin Pharmacol. 2011;73:27-36.

212. Delattre IK, Musuamba FT, Jacqmin P, Taccone FS, Laterre P-F, Verbeeck RK, Jacobs F, Wallemacq P. Population pharmacokinetics of four $\beta$-lactams in critically ill septic patients co-medicated with amikacin. Clin Biochem. 2012; 45:780-6.

Ready to submit your research? Choose BMC and benefit from:

- fast, convenient online submission

- thorough peer review by experienced researchers in your field

- rapid publication on acceptance

- support for research data, including large and complex data types

- gold Open Access which fosters wider collaboration and increased citations

- maximum visibility for your research: over $100 \mathrm{M}$ website views per year

At $\mathrm{BMC}$, research is always in progress.

Learn more biomedcentral.com/submissions 